Check for updates

Cite this: RSC Adv., 2017, 7, 28853

\title{
C-Glycosylated cinnamoylfuran derivatives as novel anti-cancer agents $\dagger$
}

\author{
Ananya Dutta, ${ }^{a}$ Debashis Dhara,,$^{a}$ Pravat Kumar Parida, ${ }^{a}$ Anshupriya $\mathrm{Si}^{a}{ }^{a}$

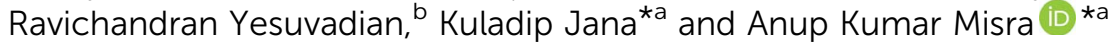

\begin{abstract}
A series of $C$-glycosylated cinnamoylfuran derivatives were synthesized in excellent yield from free sugars. The $C$-glycosylated furan derivatives were prepared under aqueous reaction conditions. The anticancer potentials of the synthesized compounds were evaluated on the basis of their comparative cytotoxic effects on cancer cells (MCF-7 and HeLa) and normal cells (NKE). Among 28 compounds evaluated for their cytotoxic effects on cancer cells, three compounds (compounds 8, 24 and 28) were shown to have significant cytotoxic effects on MCF-7 and HeLa cell lines and comparatively less toxicity against normal NKE cell line. Based on its selectivity index, compound 24 was considered the most promising anticancer agent amongst the above three compounds. Further biochemical studies with compound 24 showed that both intrinsic and extrinsic pathways of apoptosis contribute to compound 24 mediated cytotoxicity.
\end{abstract}

Received 13th April 2017

Accepted 20th May 2017

DOI: $10.1039 / \mathrm{c} 7 \mathrm{ra0} 4207 \mathrm{~h}$

rsc.li/rsc-advances

filarial agents. ${ }^{22}$ Inspired by these earlier reports, it was decided to synthesize a series of $C$-glycosylated cinnamoylfuran derivatives to evaluate their potential against cancer cell lines to develop novel anticancer agents. It was envisioned that the presence of a $C$-glycosylated furan moiety as well as an aryl cinnamoyl functionality in the molecules could improve their efficacy to act as effective cytotoxic agents against cancer cells. The $C$-glycosylated furan derivatives containing an $\alpha$-methylcarbonyl functionality were prepared from commercially available reducing sugars under aqueous reaction conditions, following an earlier report. ${ }^{23,24}$ The furan derivatives were treated with a number of aryl aldehydes in the presence of a base to furnish the desired compounds. Some selected $C$ cinnamoylated products were acetylated to check whether the $O$-acetyl group has any influence on the biological activities. The synthesized compounds (7-34) were evaluated for their cytotoxicity potential against two cancer cell lines (MCF-7 and HeLa) as well as a normal cell line (NKE). The synthesis of a series of novel $C$-glycosyl cinnamoylfuran derivatives and their potential as anticancer agents are reported herein.

therapeutic potential. ${ }^{10-15}$ In addition, a variety of cinnamoylated $C$-glycoside derivatives have been synthesized with a similar sugar moiety but different aryl groups and evaluated for their potential as anti-mycobacterial agents, ${ }^{16,17}$ anti-cancer agents, ${ }^{18}$ lectin inhibitors, ${ }^{19,20}$ enzyme inhibitors, ${ }^{21}$ and anti-

${ }^{a}$ Bose Institute, Division of Molecular Medicine, P-1/12, C.I.T. Scheme VII-M, Kolkata-700054, India. E-mail: akmisra69@gmail.com; Fax: +91 332355 3886; Tel: +913325693240

${ }^{b}$ Department of Biotechnology, School of Bioengineering, SRM University, Kattankulathur - 603203, Tamil Nadu, India

$\dagger$ Electronic supplementary information (ESI) available: Copies of 1D and 2D NMR spectra of compounds 7-34. See DOI: 10.1039/c7ra04207h

$\ddagger$ Contributed equally.

\section{Results and discussion}

\section{Chemistry}

Synthesis of $C$-glycosylated cinnamoylfuran derivatives. A series of $C$-glycosylated cinnamoyl furan derivatives (7-34) were synthesized from D-glucose, D-galactose and D-xylose following a two-step reaction sequence. Following earlier reported reaction conditions, ${ }^{23}$ treatment of D-glucose (1), D-galactose (2) and Dxylose (3) with pentane-2,4-dione in the presence of $\mathrm{CeCl}_{3} \cdot 7 \mathrm{H}_{2} \mathrm{O}$ in water furnished the corresponding $C$-glycosylated furan derivatives, such as 3-acetyl-5- $C$-glycosyl-2-methylfurans 4 (90\%) 
Table 1 Optimization of the preparation of $C$-glycosylated cinnamoyl furan derivatives

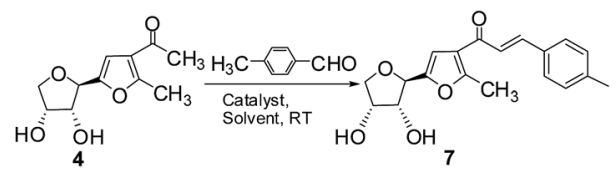

\begin{tabular}{llllll}
\hline Sl. no. & Base & Equiv. & Solvent & Time (h) & Yield (\%) \\
\hline 1 & $\mathrm{NaOH}$ & 1.0 & $\mathrm{CH}_{3} \mathrm{OH}$ & 12 & 50 \\
2 & $\mathrm{NaOCH}_{3}$ & 1.0 & $\mathrm{CH}_{3} \mathrm{OH}$ & 12 & 75 \\
3 & $\mathrm{NaOC}_{2} \mathrm{H}_{5}$ & 1.0 & $\mathrm{C}_{2} \mathrm{H}_{5} \mathrm{OH}$ & 16 & 60 \\
4 & Piperidine & 1.0 & $\mathrm{CH}_{3} \mathrm{OH}$ & 24 & 50 \\
5 & DBU & 1.0 & $\mathrm{CH}_{3} \mathrm{OH}$ & 24 & 40
\end{tabular}

and 5 (90\%) and 3-acetyl-5-(1,2,3-trihydroxypropyl)-2-methylfuran $6(85 \%)$, respectively, with an $\alpha$-methylcarbonyl functionality attached to them. In order to synthesize a series of cinnamoyl derivatives under a base mediated aldol condensation of aryl aldehydes with compounds 4-6, compound 4 was initially allowed to react with 4-methylbenzaldehyde in the presence of a series of bases ( $\mathrm{NaOH}, \mathrm{NaOCH}_{3}$, NaOEt, piperidine, DBU) (1.0 equiv.) in alcohol (Table 1). After a set of optimizations, it was found that the use of 1.0 equiv. of sodium methoxide furnished an excellent yield (75\%) of the desired product (7) in $12 \mathrm{~h}$. Therefore, compound 4 was allowed to condense with a series of aromatic aldehydes in the presence of sodium methoxide in methanol to give $C$-glycosylated cinnamoyl furan derivatives (724) in excellent yield. The formation of the trans-cinnamoyl double bonds ( $E$-isomers) in the molecules was confirmed from a ${ }^{1} \mathrm{H}$ NMR spectral analysis [doublets with large coupling constant $(J=15.5-16.0 \mathrm{~Hz})]$. It is noteworthy that the formation of other isomers was not observed under the aldol reaction conditions. Acetylation of compounds 23 and 24 using acetic

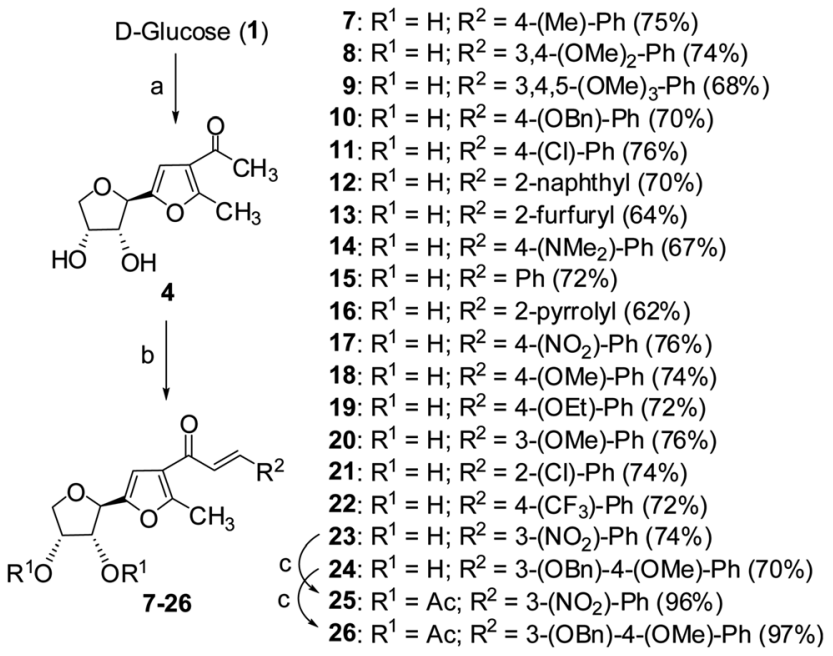

Scheme 1 Reagents and conditions: (a) pentane-2,4-dione, $\mathrm{CeCl}_{3}$ . $7 \mathrm{H}_{2} \mathrm{O}, \mathrm{H}_{2} \mathrm{O}, 90^{\circ} \mathrm{C}, 6 \mathrm{~h}, 90 \%$; (b) $\mathrm{ArCHO}, \mathrm{CH}_{3} \mathrm{ONa}, \mathrm{CH}_{3} \mathrm{OH}, \mathrm{rt}, 12 \mathrm{~h}$; (c) acetic anhydride, pyridine, $r \mathrm{r}, 3 \mathrm{~h}$.
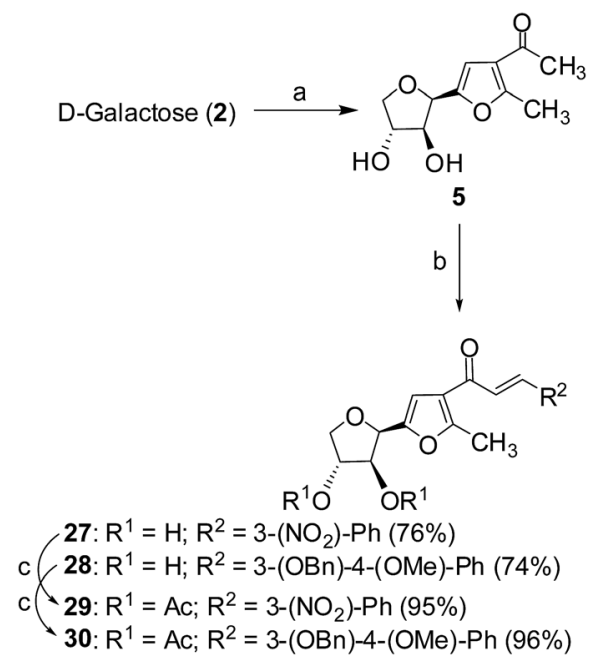

Scheme 2 Reagents and conditions: (a) pentane-2,4-dione, $\mathrm{CeCl}_{3}$ . $7 \mathrm{H}_{2} \mathrm{O}, \mathrm{H}_{2} \mathrm{O}, 90^{\circ} \mathrm{C}, 6 \mathrm{~h}, 90 \%$; (b) $\mathrm{ArCHO}, \mathrm{CH}_{3} \mathrm{ONa}, \mathrm{CH}_{3} \mathrm{OH}, \mathrm{rt}, 12 \mathrm{~h}$; (c) acetic anhydride, pyridine, rt, $3 \mathrm{~h}$.<smiles>[R]C=CC(=O)c1cc(C([R20])C(C[R10])CO[R10])oc1C</smiles>

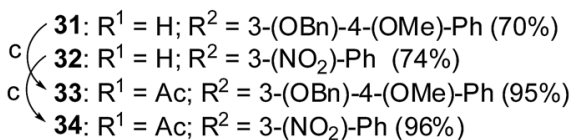

Scheme 3 Reagents and conditions: (a) pentane-2,4-dione, $\mathrm{CeCl}_{3}$ . $7 \mathrm{H}_{2} \mathrm{O}, \mathrm{H}_{2} \mathrm{O}, 90^{\circ} \mathrm{C}, 6 \mathrm{~h}, 85 \%$; (b) $\mathrm{ArCHO}, \mathrm{CH}_{3} \mathrm{ONa}, \mathrm{CH}_{3} \mathrm{OH}, \mathrm{rt}, 12 \mathrm{~h}$; (c) acetic anhydride, pyridine, rt, $3 \mathrm{~h}$.

anhydride and pyridine furnished acetylated derivatives 25 and 26 in quantitative yield (Scheme 1). Following similar reaction conditions, compounds 27 and 28 were prepared from compound 5 in very good yield, which were then acetylated to give compounds 29 and $\mathbf{3 0}$ (Scheme 2). Compounds $\mathbf{3 1}$ and $\mathbf{3 2}$ were synthesized from D-xylose derived compound $\mathbf{6}$ in very good yield, which were acetylated to give compounds 33 and $\mathbf{3 4}$ (Scheme 3). Earlier it was observed that $O$-acetylated cinnamoyl $C$-glycoside derivatives showed better antifilarial activities via an apoptotic pathway than non-O-acetylated compounds. ${ }^{22}$ This could happen due to the increase in lipophilicity in the compounds because of the presence of acetyl groups. Based on this observation, we have prepared some acetylated derivatives $(25,26,29,30,33$ and 34) to compare the cytotoxic activities of $O$ acetylated and non-O-acetylated compounds against cancer and normal cell lines. All synthesized compounds were characterized using spectral analysis. 
Table 2 The $\mathrm{IC}_{50}(\mu \mathrm{M})$ values of the compounds for the inhibition of proliferation $^{a}$

\begin{tabular}{|c|c|c|c|}
\hline Compd & MCF-7 & HeLa & NKE \\
\hline 7 & $\geq 60$ & $\geq 60$ & - \\
\hline 8 & $17.77 \pm 1.46$ & $15.98 \pm 1.85$ & $46.03 \pm 10.56$ \\
\hline 9 & $\geq 60$ & $10.93 \pm 5.36$ & $109 \pm 7.85$ \\
\hline 10 & $64.54 \pm 13.16$ & $\geq 60$ & $75.07 \pm 27.83$ \\
\hline 11 & $\geq 60$ & $\geq 60$ & - \\
\hline 12 & $\geq 60$ & $\geq 60$ & - \\
\hline 13 & $\geq 60$ & $\geq 60$ & - \\
\hline 14 & $68.75 \pm 12.84$ & $81.48 \pm 76.22$ & $\geq 60$ \\
\hline 15 & $90.77 \pm 105.53$ & $35.93 \pm 10.13$ & $59.05 \pm 59.05$ \\
\hline 16 & $54.07 \pm 6.49$ & $\geq 60$ & $\geq 60$ \\
\hline 17 & $\geq 60$ & $\geq 60$ & - \\
\hline 18 & $\geq 60$ & $\geq 60$ & - \\
\hline 19 & $43.49 \pm 7.39$ & $47.58 \pm 10.37$ & $\geq 60$ \\
\hline 20 & $\geq 60$ & $\geq 60$ & - \\
\hline 21 & $45.37 \pm 14.31$ & $\geq 60$ & $99.92 \pm 27.89$ \\
\hline 22 & $33.0 \pm 1.5$ & $\geq 60$ & $24.38 \pm 11.38$ \\
\hline 23 & $\geq 60$ & $\geq 60$ & - \\
\hline 24 & $9.588 \pm 5.25$ & $14.22 \pm 3.94$ & $54.14 \pm 1.56$ \\
\hline 25 & $\geq 60$ & $\geq 60$ & - \\
\hline 26 & $\geq 60$ & $\geq 60$ & - \\
\hline 27 & $32.35 \pm 3.6$ & $\geq 60$ & $\geq 60$ \\
\hline 28 & $22.98 \pm 4.19$ & $22.29 \pm 4.03$ & $40.29 \pm 11.87$ \\
\hline 29 & $34.79 \pm 6.86$ & $\geq 60$ & $\geq 60$ \\
\hline 30 & $\geq 60$ & $\geq 60$ & - \\
\hline 31 & $43.84 \pm 7.66$ & $30.25 \pm 6.76$ & $30.23 \pm 23$ \\
\hline 32 & $\geq 60$ & $\geq 60$ & - \\
\hline 33 & $91.27 \pm 53.63$ & $\geq 60$ & $23.84 \pm 17.45$ \\
\hline 34 & $\geq 60$ & $\geq 60$ & - \\
\hline Etoposide & $24.77 \pm 3.4$ & $29.12 \pm 8.56$ & - \\
\hline
\end{tabular}

${ }^{a} \mathrm{IC}_{50}=$ concentration at which $50 \%$ inhibition in motility was achieved.

\section{Biology}

Cytotoxic effect of $\boldsymbol{C}$-glycosyl cinnamoylfuran derivatives by MTT cell proliferation assay. The newly synthesized $C$-glycosyl3-cinnamoylfuran derivatives (7-34) were screened in vitro for their anti-proliferative effect on MCF-7 (Human breast carcinoma), HeLa (Human cervical carcinoma) and NKE (Normal Kidney Epithelial) cells. MCF-7 is the most studied human breast cancer cell line and results from this cell line have had a fundamental impact upon breast cancer research and patient outcomes. The MCF-7 cell line is one of a very few breast cancer cell lines that expresses substantial levels of ER, mimicking the majority of invasive human breast cancers that express ER. ${ }^{25}$ Similarly, HeLa has been widely used as a model for cervical cancer over the past 50 years of cervical cancer research. ${ }^{26}$ Owing to these facts we chose these two cells lines for our experiments. Etoposide was used as a standard control, considering its tremendous anti-proliferative activity. ${ }^{27}$ In this experiment, MCF-7, HeLa and NKE cells were treated with various concentrations $(0 \mu \mathrm{M}, 5 \mu \mathrm{M}, 10 \mu \mathrm{M}, 20 \mu \mathrm{M}, 30 \mu \mathrm{M}$ and $50 \mu \mathrm{M}$ ) of the $C$-glycoside derivatives and the cell viability was measured by MTT assay. ${ }^{28}$ The results are summarized in Table 2 and expressed in terms of $\mathrm{IC}_{50}$ values (half-maximal inhibitory concentration).
Out of 28 tested compounds, compound $8\left(\mathrm{IC}_{50}: 17.77 \pm 1.46\right.$ $\mu \mathrm{M})$, compound $24\left(\mathrm{IC}_{50}: 9.588 \pm 5.25 \mu \mathrm{M}\right)$ and compound 28 $\left(\mathrm{IC}_{50}: 22.98 \pm 4.19 \mu \mathrm{M}\right)$ showed higher efficacy than etoposide $\left(\mathrm{IC}_{50}: 24.77 \pm 3.4 \mu \mathrm{M}\right)$ in MCF-7 cells. In another set of HeLa cells, compound $8\left(\mathrm{IC}_{50}: 15.98 \pm 1.85 \mu \mathrm{M}\right)$, compound $24\left(\mathrm{IC}_{50}\right.$ : $14.22 \pm 3.94 \mu \mathrm{M})$, compound $28\left(\mathrm{IC}_{50}: 22.29 \pm 4.03 \mu \mathrm{M}\right)$ and also compound $9\left(\mathrm{IC}_{50}: 10.93 \pm 5.36 \mu \mathrm{M}\right)$ exerted lower $\mathrm{IC}_{50}$ as compared to etoposide $\left(\mathrm{IC}_{50}: 29.12 \pm 8.56 \mu \mathrm{M}\right)$. From these results, it was found that compound 24 was more potent in both MCF-7 and HeLa cells as compared to compound 8 and compound 28, whereas compound $\mathbf{9}$ was only effective in HeLa cells. Consequently, an evaluation of the cytotoxic effect of compounds 8, 24 and 28 against NKE cells showed significantly higher $\mathrm{IC}_{50}$ values than their $\mathrm{IC}_{50}$ values against MCF-7 and HeLa cells [compound $24\left(\mathrm{IC}_{50}: 54.14 \pm 1.56 \mu \mathrm{M}\right)$, compound 8 $\left(\mathrm{IC}_{50}: 46.03 \pm 10.56 \mu \mathrm{M}\right)$ and compound $28\left(\mathrm{IC}_{50}: 40.29 \pm 11.87\right.$ $\mu \mathrm{M})]$. Subsequently, when the selectivity indexes (SI) were calculated based on the $\mathrm{IC}_{50}$ value ratio of compounds in NKE vs. MCF-7, it was found that compound $24(\mathrm{SI}=7.93 \pm 4.18)$ possessed higher SI in comparison to compound 8 ( $\mathrm{SI}=2.56 \pm$ 0.38 ) and compound 28 ( $\mathrm{SI}=4.05 \pm 0.06)$. In the case of HeLa cells, compound 24 also showed a better SI value than the other two compounds [compound 24 ( $\mathrm{SI}=3.42 \pm 0.30), 8(\mathrm{SI}=3.33 \pm$ $0.34)$ and $28(\mathrm{SI}=1.71 \pm 0.20)]$.

The activity of compound 24 was further tested against MDAMB-231 cells. Interestingly, it was also observed that compound 24 was very effective in inhibiting the proliferation of MDA-MB231 cells and the calculated $\mathrm{IC}_{50}$ value was $19.16 \pm 5.97 \mu \mathrm{M}$ (Fig. 1). Based on the preliminary MTT experimental data and selectivity index, compound $\mathbf{2 4}$ has been selected as a promising anti-cancer agent and considered for further evaluation.

Treatment with compound 24 exhibited a significant decrease in the cell reproductive death (colony formation) in MCF-7 cells. Clonogenic assay or colony formation assay, ${ }^{29}$ an in vitro cell survival assay, was performed in MCF-7 cells using compound 24 to check the ability of a single cell to grow into a colony in the presence of different doses of the compound $(0 \mathrm{nM}, 100 \mathrm{nM}, 500 \mathrm{nM}, 1.25 \mu \mathrm{M}, 2.5 \mu \mathrm{M}$ and $5 \mu \mathrm{M}$ ) for 15 days. Interestingly, counting of colonies clearly demonstrated that compound 24 significantly decreased the colony numbers in MCF-7 cells even at a dose of $1.25 \mu \mathrm{M}$ (Fig. 2). At a dose of $5 \mu \mathrm{M}$ of compound 24, not a single colony was observed, as shown in Fig. 2.

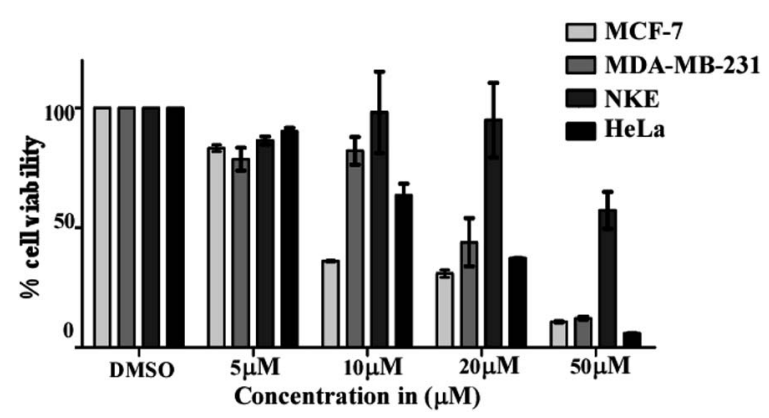

Fig. 1 Determination of dose-dependent cytotoxicity of compound 24 on various human cell lines. 

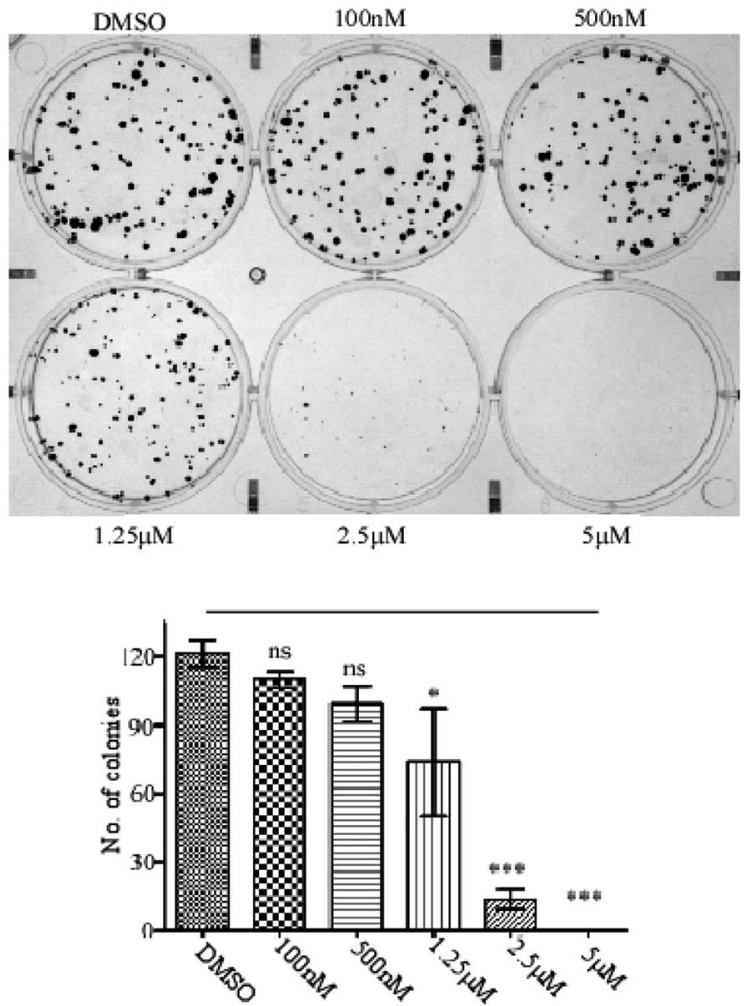

Fig. 2 Effects of compound 24 on colony formation on MCF-7 cells The results show a minimum of three independent experiments and the bar graph shows mean \pm SEM $\left(* p<0.05,{ }^{* *} p<0.01, * * * p<0.001\right.$, $\mathrm{ns}=$ not significant)

Compound 24 mediated G2/M arrest contributes to growth inhibition in MCF-7 cells. The cell cycle process has a critical role in the cellular growth process. In order to check whether compound 24 mediated inhibition of cancer cell proliferation has any relationship with cell cycle arrest, MCF-7 cells were treated with varying concentrations of compound $24(0 \mu \mathrm{M}, 5$ $\mu \mathrm{M}, 10 \mu \mathrm{M}, 20 \mu \mathrm{M}$ and $30 \mu \mathrm{M})$ for $24 \mathrm{~h}$ and stained with propidium iodide and the cell cycle profile checked in FACs. Interestingly, it was found that there was an increase in the percentage of cells in the G2/M phase of the cell cycle $(19.4 \%$, $29.6 \%, 34.2 \%, 37.1 \%, 45.2 \%$ ), as is evident from Fig. $3.2 \mu \mathrm{M}$ of nocodazole was used as a positive control $^{30}$ for G2/M arrest, where $81.7 \%$ cells were found in the G2/M phase. From this experiment it was confirmed that compound $\mathbf{2 4}$ mediated apoptosis G2/M arrest contributes to the growth inhibition in MCF-7 cells.

Treatments with compound 24 induced significant apoptosis in MCF-7 cells. Apoptosis is a crucial phenomenon which blocks the proliferation of cells. ${ }^{31}$ In order to check whether compound $\mathbf{2 4}$ mediated inhibition of cancer cell proliferation has any relationship with apoptosis, we treated MCF-7 cells with varying concentrations of compound $24(0 \mu \mathrm{M}$, $5 \mu \mathrm{M}, 10 \mu \mathrm{M}, 20 \mu \mathrm{M}$ and $30 \mu \mathrm{M})$ and stained with annexin VFITC/PI for analysis of apoptotic cells. Interestingly, $6.11 \pm$ $0.11 \%, 14.71 \pm 1.29 \%, 15.82 \pm 1.78 \%, 28.46 \pm 10.36 \%$ cells were found to have annexin $\mathrm{V}$-FITC ${ }^{+} / \mathrm{PI}^{-}$and annexin $\mathrm{V}-\mathrm{FITC}^{+} /$

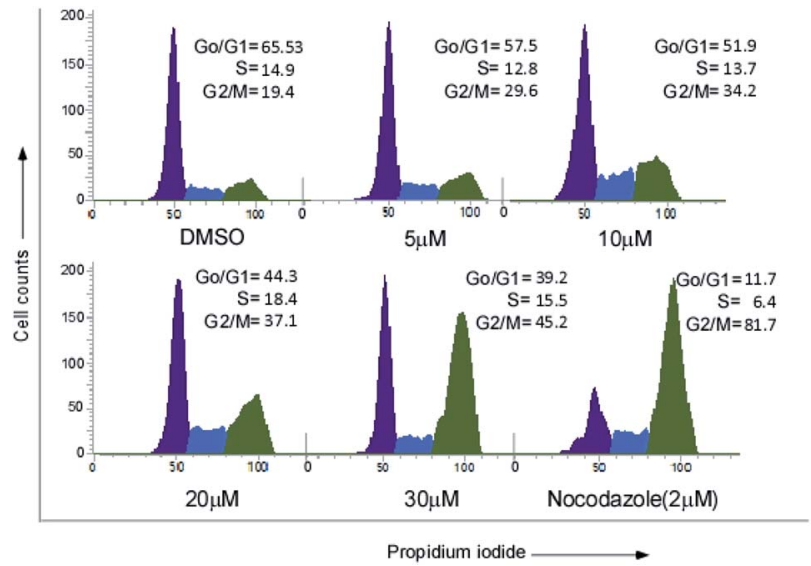

Fig. 3 Compound 24 induced G2/M phase cell cycle arrest in MCF-7 cells.

$\mathrm{PI}^{+}$when treated with concentrations of $5 \mu \mathrm{M}, 10 \mu \mathrm{M}, 20 \mu \mathrm{M}, 30$ $\mu \mathrm{M}$, respectively, in comparison with a vehicle control $(4.22 \pm$ $0.45 \%$ ). Thus, the apoptotic potential of compound 24 has been established by this experiment. MCF-7 cells were shown to be prone to apoptosis in a dose-dependent manner except for doses of $10 \mu \mathrm{M}$ and $20 \mu \mathrm{M}$, where a dose-dependent increase in

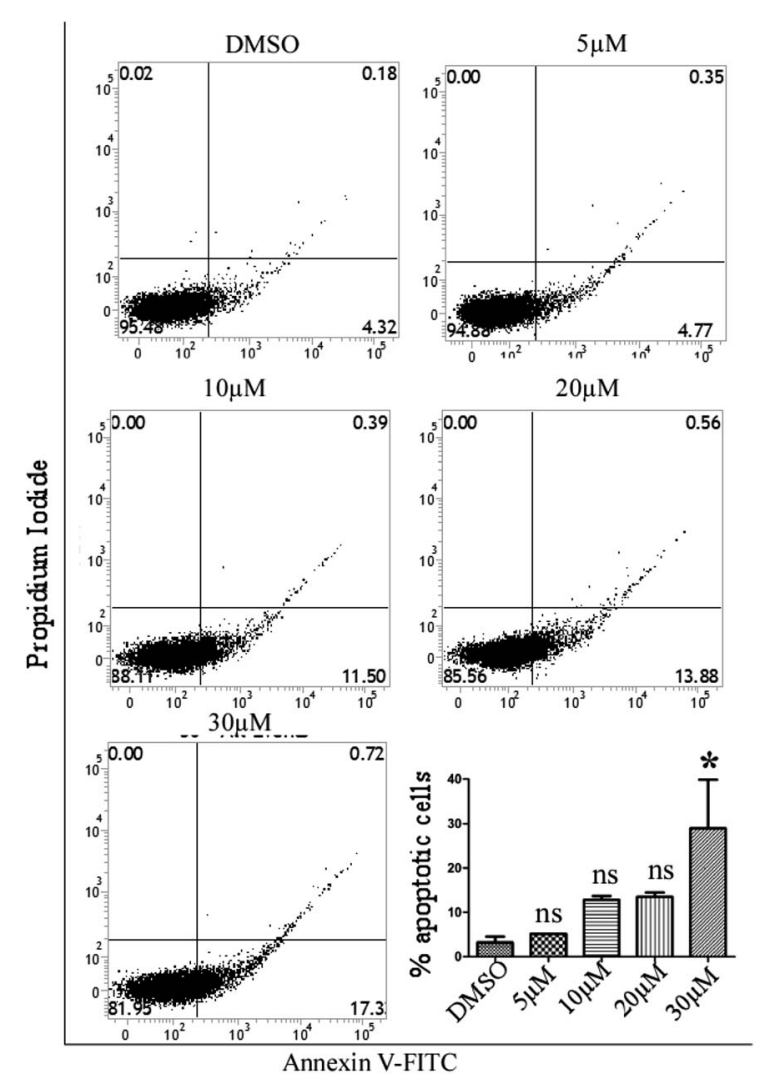

Fig. 4 Demonstrates the apoptosis-inducing ability of compound 24 in the MCF-7 cell line. After treatment with compound 24, the MCF-7 cells were incubated with $5 \mu \mathrm{l}$ of annexin V-FITC and $5 \mu \mathrm{l}$ of PI for $15 \mathrm{~min}$ at room temperature and flow cytometric analysis was performed. 

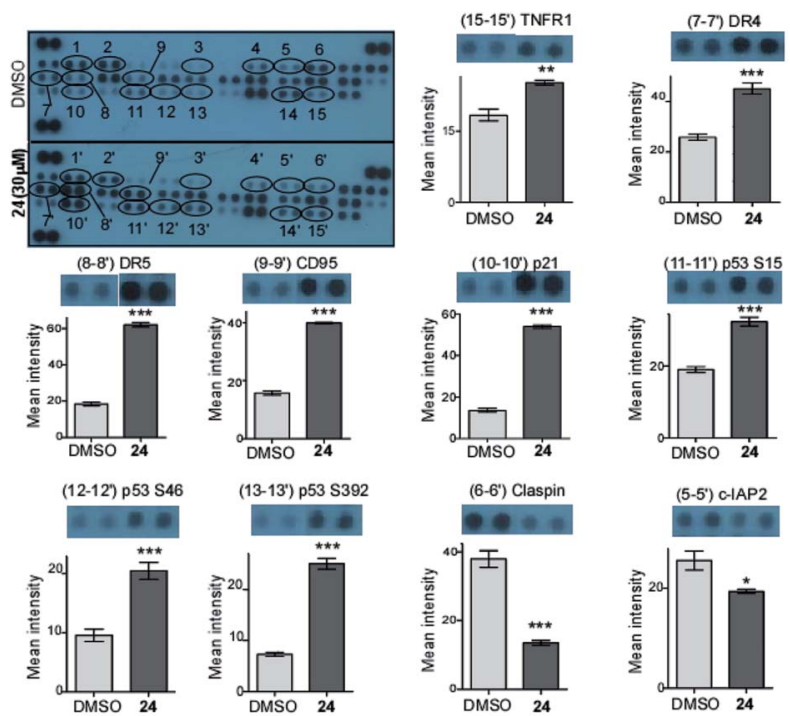

(13-13') p53 S392
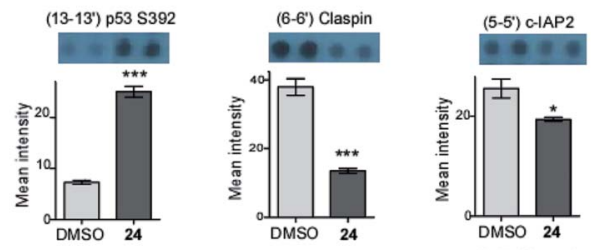

(14-14') Survivin
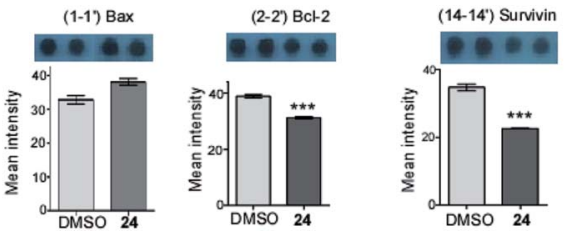
(3-3) Cleaved

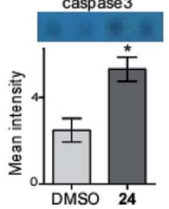

Fig. 5 The Human Apoptosis Array detects the expression of multiple apoptosis-related proteins in treated and untreated MCF-7 cells. The bar graphs indicate the band intensity. Data are representative of two independent experiments and bar graph shows mean \pm SEM $(* p<$ $0.05, * * p<0.01, * * * p<0.001, \mathrm{~ns}=$ not significant).

apoptosis was not prominent. This significantly elevated level of apoptosis, confirmed through annexin $\mathrm{V}$ binding with translocated phosphatidylserine, provided a clue that the process of apoptosis definitely contributes to the compound 24 mediated cytotoxicity (Fig. 4).

Human apoptosis proteome profile array demonstrated compound 24 induced increase in pro-apoptotic and decrease in anti-apoptotic proteins in MCF-7 cell line. Annexin V-FITC staining confirmed that apoptosis is one of the key processes contributing to the compound $\mathbf{2 4}$ mediated cytotoxicity. In order to gain a comprehensive idea regarding the molecular changes in the expression level of several proteins associated with apoptosis machinery, a Human Apoptosis Array kit (R\&D Biosystem) was used. MCF-7 cells were treated with $30 \mu \mathrm{M}$ of compound 24 for 48 hours and lysates were used to profile the expression level of 35 proteins associated with the apoptosis machinery. Analysis of membranes indicated the differential expression of several apoptosis-related proteins, as shown in Fig. 5. Interestingly, the dot images of the Human Apoptosis Array kit showed significant down-regulation of several antiapoptotic proteins, including Bcl-2, survivin, cIAP1, cIAP2 as well as claspin. In contrast, pro-apoptotic protein Bax and p21 were significantly up-regulated due to treatment with compound 24. Since the Bax/Bcl-2 ratio plays a critical role in the apoptosis process, compound $\mathbf{2 4}$ probably mediates apoptosis by changing the $\mathrm{Bax} / \mathrm{Bcl}-2$ ratio. In addition, we also observed a significant increase in the expression of some

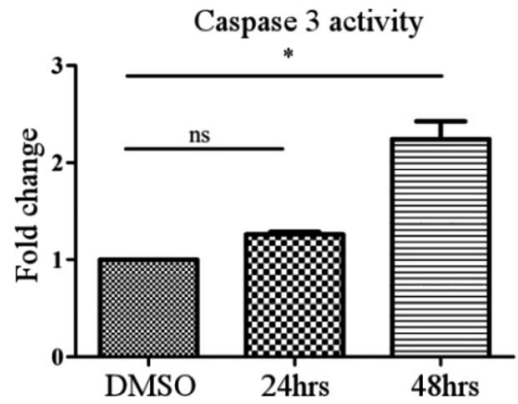

Fig. 6 Caspase-3 cleavage activity in MCF-7 cell extracts after treatment with compound 24. Caspase-3 activity was measured by determining the ability of cell extracts to cleave the colorimetric substrate, Ac-DEVD-pNA, and plotted as a concentration in $\mu \mathrm{M}$ of the cleaved $\mathrm{pNA}$ in the extract. Data represent the means \pm SEM of 2 independent experiments. ${ }^{*} P<0.01$ and $\mathrm{ns}=$ non significant represent significant differences compared to the control condition.

proteins (TNFR1, CD4/TRAIL-1, CD5/TRAIL-2, CD95/Fas) that help in the receptor-mediated programmed cell death process. More importantly, a significant increase in the expression of cleaved caspase 3 was observed under treated conditions as compared to the control condition (Fig. 4). In addition, a human apoptosis proteome profile array using MCF-7 cells showed that treatment with compound $\mathbf{2 4}$ resulted in an increase in the expression of several pro-apoptotic proteins (Bax, p21 p53 etc.) and a decrease in the expression of antiapoptotic proteins (survivin, claspin, bcl-2, etc.), as shown in Fig. 4. This imbalance between pro-apoptotic and anti-apoptotic proteins within the cells leads to apoptosis. It is well established that p53 phosphorylation at ser15 (DNA damage response) (2,33 $^{32,3}$ ser 46 (induction of apoptosis) (3,35 $^{34}$ and ser 392 (growth suppression $)^{36}$ plays an important role in cell proliferation. Interestingly, an increased level of total p53 along with p-p53 ser15, ser46, and ser392 was observed from proteome profiling and Western-immunoblotting analysis (Fig. 5). These findings suggested that both intrinsic as well as extrinsic apoptosis pathways contribute to compound $\mathbf{2 4}$ mediated apoptosis.

Caspase 3 activity assay. Since, caspase-3 activity is the key factor in apoptosis induction, it was decided to carry out a caspase-3/7 activity assay (colorimetric) using compound 24 to establish its potential to induce apoptosis. ${ }^{37}$ In MCF-7 cells, a 2fold increase in caspase activity was measured at a concentration of $30 \mu \mathrm{M}$ when compared with the control. Interestingly, such a level of caspase activation can be considered sufficient to cause cell death and the results clearly indicated that the cell death was induced by increased caspase-3 activities (Fig. 6).

Quantitative structure activity relationship analysis. In order to gain further information about the structure-function relationship of the active compounds, 3D-QSAR analyses of the active compounds were carried out using the Schrödinger program. ${ }^{38}$ Model building was performed using partial leastsquares regression (PLS). ${ }^{39}$ The $3 \mathrm{D}-\mathrm{QSAR}$ study described the pharmacophoric features of $C$-glycosylated cinnamoylfuran derivatives that contribute most towards the elicitation of an 
Table 3 Statistical results for 3D-QSAR model ${ }^{a}$

\begin{tabular}{ll}
\hline Training set & Test set \\
\hline$N_{1}=18$ & $N_{2}=9$ \\
Corr. coefficient $=0.9407$ & Corr. coefficient $=0.8694$ \\
RMSD $=0.1995$ & RMSD $=0.2631$ \\
Max. fit value $=7.9529$ & Max. fit value $=3.9561$ \\
Weight $=1.1257$ & Weight $=1.1276$ \\
${ }^{a} N_{1}$ and $N_{2}:$ number of molecules in the training and test set, \\
respectively; RMSD: root-mean square deviation.
\end{tabular}
respectively; RMSD: root-mean square deviation.
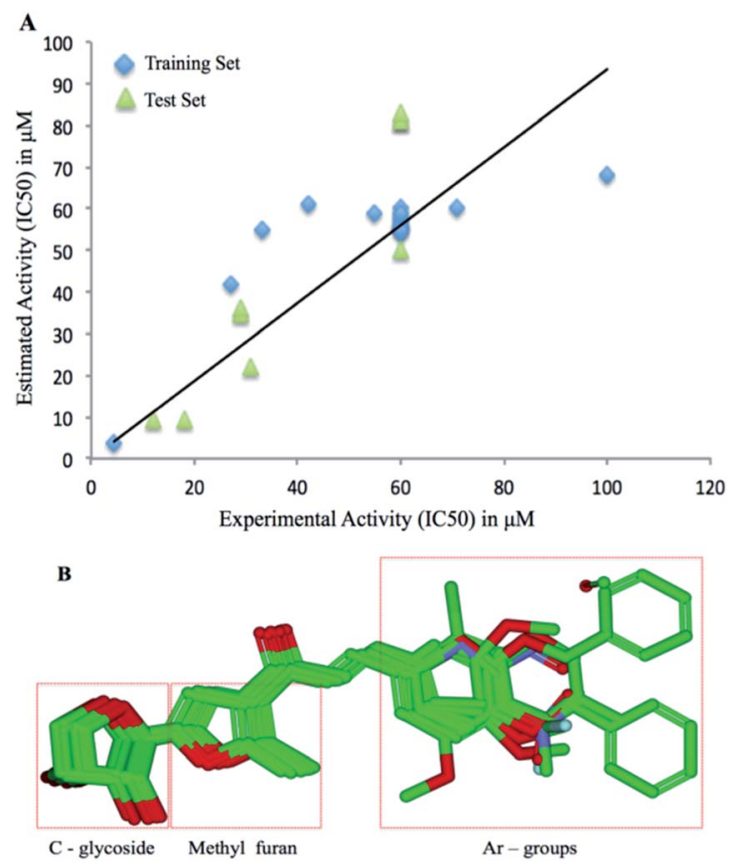

Fig. 7 3D-QSAR analysis of the compounds evaluated for anti-cancer activities. (A): Regression plot representing the statistical analysis with reference to the predicted $I C_{50}$ value and theoretical $I C_{50}$ values. $(B)$ : Alignment of the molecules showing conserved C-glycosylfuran moiety and variable aryl groups.

anti-cancer property. To analyze the anti-cancer property of the selected data set compounds (28 molecules) by 3D-QSAR analyses, they were categorized into a training set (19 molecules) and a test set ( 9 molecules). The statistical significance of this model is given in Table 3. The training set molecules exhibited a higher fit value and correlation coefficient and a lower RMSD value, which denote the excellence of accommodating the active groups of the molecules in the pharmacophoric features. The correlation between the experimental $\mathrm{IC}_{50}$ and the estimated $\mathrm{IC}_{50}$ values of the training set and the test set molecules are shown in Fig. 7A. The alignment of the molecular conformations confirmed that the $C$-glycosylated furan moiety present in all molecules is the essential feature eliciting an anti-cancer response (Fig. 7B). Mapping of the most active compounds 24 and $\mathbf{8}$ with the pharmacophore model has shown excellent interaction with all pharmacophoric features. Whereas mapping of the least active compounds 15 and 19 did not exhibit the interactions of their functional groups with all pharmacophoric features (Figure not shown). Substitution with an electron-donating alkyl group in the meta- and para- positions of the aromatic group (phenyl ring) increased the anticancer activity (compounds 8 and 24). The methyl group of the furan ring imparts hydrophobic interaction, which is also essential for improving affinity towards the target as an anticancer compound.

\section{Conclusions}

In summary, a series of $C$-glycosyl cinnamoylfuran derivatives were synthesized and evaluated for their in vitro cytotoxic activity against cancer cells (MCF-7 and HeLa) and normal cells (NKE). Three compounds (8, 24 and 28) showed significant cytotoxic effects on MCF-7 and HeLa cell lines. Based on the selectivity index, compound $\mathbf{2 4}$ was considered the most promising anticancer agent. Further biochemical studies showed that compound $\mathbf{2 4}$ mediated cytotoxicity appeared to be due to both intrinsic and extrinsic pathways of apoptosis. QSAR studies have also been carried out to establish the structureactivity relationships of the active compounds.

\section{Experimental}

\section{General methods}

All reactions were monitored by thin layer chromatography over silica gel coated TLC plates. The spots on TLC were visualized by warming ceric sulphate $\left(2 \% \mathrm{Ce}\left(\mathrm{SO}_{4}\right)_{2}\right.$ in $\left.2 \mathrm{~N} \mathrm{H}_{2} \mathrm{SO}_{4}\right)$ sprayed plates on a hot plate. Silica gel 230-400 mesh was used for column chromatography. ${ }^{1} \mathrm{H}$ and ${ }^{13} \mathrm{C}$ NMR, 2D COSY, HSQC spectra were recorded on a Bruker Avance $500 \mathrm{MHz}$ spectrometer using $\mathrm{CDCl}_{3}$ as solvent and TMS as the internal reference unless stated otherwise. Chemical shift values are expressed in $\delta$ ppm. ESI-MS were recorded on a Micromass mass spectrometer. Elementary analysis was carried out on a Carlo Erba analyzer. Optical rotations were measured at $25^{\circ} \mathrm{C}$ on a Jasco P2000 polarimeter. Biological experiments were carried out in a Shimadzu UV-2401PC spectrophotometer. Commercially available grades of organic solvents of adequate purity were used in many reactions. The cell culture media along with ingredients were purchased from HiMedia (India). FBS was procured from Gibco (USA). DMSO was purchased from SRL (India). An annexin V-FITC apoptosis assay kit was bought from BD Bioscience (India). A Caspase 3 Assay Kit (ab39401) and Human Apoptosis Array Kit were purchased from AbCam (UK) and R\&D Systems (USA), respectively. MCF-7, MDA-MB-231 (human breast cancer) cells, HeLa (human cervical cancer) cells were obtained from the central cell repository of National Center for Cell Science (NCCS), Pune, India. Normal Kidney Epithelial cell (NKE) was a kind gift from Dr K. Biswas, Bose Institute, Kolkata. The cell lines were cultured in RPMI-1640 or DMEM supplemented with $10 \%$ FBS, $1 \mathrm{mM}$ sodium pyruvate, $2 \mathrm{mM}$ L-glutamine, non-essential amino acids, 100 units per $\mathrm{ml}$ penicillin, $50 \mu \mathrm{g} \mathrm{ml}^{-1}$ streptomycin and $50 \mu \mathrm{g} \mathrm{ml}^{-1}$ gentamicin sulfate at $37{ }^{\circ} \mathrm{C}$ in a humidified incubator containing $5 \% \mathrm{CO}_{2}$ atmosphere. 
General experimental condition for the preparation of compound 7-34

To a solution of compound 4 or 5 or $6(1 \mathrm{mmol})$ in $\mathrm{CH}_{3} \mathrm{OH}(10$ $\mathrm{ml})$ were added aromatic aldehyde $(1.05 \mathrm{mmol})$ and $\mathrm{NaOCH}_{3}$ $(100 \mathrm{mg})$ and the reaction mixture was allowed to stir at room temperature for $12 \mathrm{~h}$. The reaction mixture was diluted with water and acidified with $1 \mathrm{~N} \mathrm{HCl}$. The white solid precipitated out from the solution, which was filtered and crystallized from EtOH to give pure products $\mathbf{7 - 3 4}$ in appropriate yield, as mentioned in the schemes.

\section{Analytical data of the compounds 7-34}

Compound 7. Yellow solid; $R_{\mathrm{f}}: 0.20$ (hexane-EtOAc; $1: 2$ ); $\mathrm{mp}$ 120-122 ${ }^{\circ} \mathrm{C}[\mathrm{EtOH}] ;[\alpha]_{\mathrm{D}}^{25}-51\left(c 1.0, \mathrm{CHCl}_{3}\right) ;{ }^{1} \mathrm{H} \mathrm{NMR}(500 \mathrm{MHz}$, $\left.\mathrm{CDCl}_{3}\right): \delta 7.71(\mathrm{~d}, 1 \mathrm{H}, J=15.5 \mathrm{~Hz}, \mathrm{COCH}=\mathrm{CH}), 7.50(\mathrm{~d}, 2 \mathrm{H}, J=$ $7.5 \mathrm{~Hz}, \operatorname{Ar}-\mathrm{H}$ ), 7.21 (d, 2H, $J=7.5 \mathrm{~Hz}, \operatorname{Ar}-\mathrm{H}), 7.14$ (d, 1H, $J=$ $15.5 \mathrm{~Hz}, \mathrm{COCH}=\mathrm{CH}), 6.72(\mathrm{~s}, 1 \mathrm{H}, \mathrm{H}-4), 4.68(\mathrm{~d}, 1 \mathrm{H}, J=6.5 \mathrm{~Hz}$, $\mathrm{H}-1^{\prime}$ ), 4.42-4.38 (m, 2H, H-4'), 4.29-4.26 (m, 1H, H-3'), 3.92 (dd, $\left.1 \mathrm{H}, J=3.0,10.5 \mathrm{~Hz}, \mathrm{H}-2^{\prime}\right), 2.65\left(\mathrm{~s}, 3 \mathrm{H}, \mathrm{CH}_{3}\right), 2.41\left(\mathrm{~s}, 3 \mathrm{H}, \mathrm{CH}_{3}\right)$; ${ }^{13} \mathrm{C}$ NMR (125 MHz, $\left.\mathrm{CDCl}_{3}\right): \delta 185.7(C=\mathrm{O}), 159.7(\mathrm{C}-4), 150.9$ $(\mathrm{C}-1), 143.5(\mathrm{COCH}=\mathrm{CH}), 140.8,132.2,129.6,128.4(\mathrm{Ar}-\mathrm{C})$, $122.6(\mathrm{COCH}=\mathrm{CH}), 122.3(\mathrm{C}-2), 109.0(\mathrm{C}-3), 77.2\left(\mathrm{C}-1^{\prime}\right), 74.8$ $\left(\mathrm{C}-3^{\prime}\right), 73.1$ (C-4'), 71.0 (C-2'), 21.5, 14.6 (2C, $\left.\mathrm{CH}_{3}\right)$; ESI-MS: 351.1 $[\mathrm{M}+\mathrm{Na}]^{+}$; anal. calcd for $\mathrm{C}_{19} \mathrm{H}_{20} \mathrm{O}_{5}(328.36)$ : C, 69.50; $\mathrm{H}, 6.14 \%$; found: $\mathrm{C}, 69.45 ; \mathrm{H}, 6.34 \%$.

Compound 8. Yellow solid; $R_{\mathrm{f}}$ : 0.22 (hexane-EtOAc; $1: 2$ ); $\mathrm{mp}$ $128-130{ }^{\circ} \mathrm{C}[\mathrm{EtOH}] ;[\alpha]_{\mathrm{D}}^{25}-34\left(c 1.0, \mathrm{CHCl}_{3}\right) ;{ }^{1} \mathrm{H} \mathrm{NMR}(500 \mathrm{MHz}$, $\left.\mathrm{CDCl}_{3}\right): \delta 7.58(\mathrm{~d}, 1 \mathrm{H}, J=16.0 \mathrm{~Hz}, \mathrm{COCH}=\mathrm{CH}), 7.10(\mathrm{~d}, 1 \mathrm{H}, J=$ $7.5 \mathrm{~Hz}, \mathrm{Ar}-\mathrm{H}$ ), 7.03 (s, 1H, Ar-H), 6.96 (d, 1H, $J=15.5 \mathrm{~Hz}, \mathrm{COCH}$ $=\mathrm{CH}), 6.79(\mathrm{~d}, 1 \mathrm{H}, J=8.0 \mathrm{~Hz}, \mathrm{Ar}-\mathrm{H}), 6.65(\mathrm{~s}, 1 \mathrm{H}, \mathrm{H}-4), 4.61(\mathrm{~d}$, $\left.1 \mathrm{H}, J=6.0 \mathrm{~Hz}, \mathrm{H}^{-1}{ }^{\prime}\right), 4.32-4.29\left(\mathrm{~m}, 2 \mathrm{H}, \mathrm{H}-4^{\prime}\right), 4.19-4.17(\mathrm{~m}, 1 \mathrm{H}$, $\left.\mathrm{H}-3^{\prime}\right), 3.86-3.82\left(\mathrm{~m}, 7 \mathrm{H}, \mathrm{H}-2^{\prime}, 2 \mathrm{OCH}_{3}\right), 2.55\left(\mathrm{~s}, 3 \mathrm{H}, \mathrm{CH}_{3}\right) ;{ }^{13} \mathrm{C}$ NMR (125 MHz, $\left.\mathrm{CDCl}_{3}\right): \delta 185.7(C=\mathrm{O}), 159.7(\mathrm{C}-4), 151.5(\mathrm{C}-1)$, 150.0, 149.2 (Ar-C), $143.8(\mathrm{COCH}=\mathrm{CH}), 127.6(\mathrm{Ar}-\mathrm{C}), 122.2$ $(\mathrm{COCH}=\mathrm{CH}), 122.3(\mathrm{C}-2), 121.5(\mathrm{Ar}-\mathrm{C}), 110.1,110.2(\mathrm{Ar}-\mathrm{C})$,

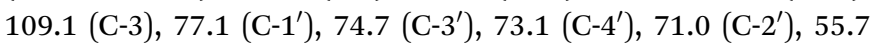
(2C, $\left.2 \mathrm{OCH}_{3}\right)$, $14.6\left(\mathrm{CH}_{3}\right)$; ESI-MS: $397.1[\mathrm{M}+\mathrm{Na}]^{+}$; anal. calcd for $\mathrm{C}_{20} \mathrm{H}_{22} \mathrm{O}_{7}$ (374.38): C, 64.16; H, 5.92\%; found: C, 64.42; H, $6.01 \%$.

Compound 9. Yellow solid; $R_{\mathrm{f}}: 0.31$ (hexane-EtOAc; $1: 2$ ); $\mathrm{mp}$ 141-142 ${ }^{\circ} \mathrm{C}[\mathrm{EtOH}] ;[\alpha]_{\mathrm{D}}^{25}-41\left(c 1.0, \mathrm{CHCl}_{3}\right) ;{ }^{1} \mathrm{H} \mathrm{NMR}(500 \mathrm{MHz}$, $\left.\mathrm{CDCl}_{3}\right): \delta 7.63(\mathrm{~d}, 1 \mathrm{H}, J=15.5 \mathrm{~Hz}, \mathrm{COCH}=\mathrm{CH}), 6.05(\mathrm{~d}, 1 \mathrm{H}, J=$ $15.5 \mathrm{~Hz}, \mathrm{COCH}=\mathrm{CH}), 6.81(\mathrm{~s}, 2 \mathrm{H}, \mathrm{Ar}-\mathrm{H}), 6.73(\mathrm{~s}, 1 \mathrm{H}, \mathrm{H}-4), 4.69$ (d, $1 \mathrm{H}, J=7.0 \mathrm{~Hz}, \mathrm{H}-1^{\prime}$ ), 4.43-4.38 (m, 2H, H-4'), 4.30 (dd, $1 \mathrm{H}, J$ $\left.=5.0,10.0 \mathrm{~Hz}, \mathrm{H}-3^{\prime}\right), 3.92-3.84\left(\mathrm{~m}, 10 \mathrm{H}, \mathrm{H}-2^{\prime}, 3 \mathrm{OCH}_{3}\right), 2.66(\mathrm{~s}$, $\left.3 \mathrm{H}, \mathrm{CH}_{3}\right) ;{ }^{13} \mathrm{C}$ NMR $\left(125 \mathrm{MHz}, \mathrm{CDCl}_{3}\right): \delta 185.4(\mathrm{C}=\mathrm{O}), 159.8(\mathrm{C}-$ 4), 153.4 (Ar-C), $149.9(\mathrm{C}-1), 143.6(\mathrm{COCH}=\mathrm{CH}), 137.7(\mathrm{Ar}-\mathrm{C})$, 130.2 (C-2), $126.2($ Ar-C), $123.0(\mathrm{COCH}=\mathrm{CH}), 109.0(\mathrm{C}-3)$,

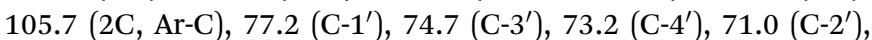
60.9, $56.1\left(3 \mathrm{C}, 3 \mathrm{OCH}_{3}\right), 14.6\left(\mathrm{CH}_{3}\right)$; ESI-MS: $427.1[\mathrm{M}+\mathrm{Na}]^{+}$; anal. calcd for $\mathrm{C}_{21} \mathrm{H}_{24} \mathrm{O}_{8}$ (404.41): C, 62.37; H, 5.98\%; found: $\mathrm{C}$, 62.47; H, 6.11\%.

Compound 10. Yellow solid; $R_{\mathrm{f}}: 0.28$ (hexane-EtOAc; $1: 2$ ); mp 99-101 ${ }^{\circ} \mathrm{C}[\mathrm{EtOH}] ;[\alpha]_{\mathrm{D}}^{25}-21$ (c 1.0, $\left.\mathrm{CHCl}_{3}\right) ;{ }^{1} \mathrm{H}$ NMR $(500$ $\left.\mathrm{MHz}, \mathrm{CDCl}_{3}\right): \delta 7.72(\mathrm{~d}, 1 \mathrm{H}, J=15.5 \mathrm{~Hz}, \mathrm{COCH}=\mathrm{CH}), 7.56(\mathrm{~d}$, $2 \mathrm{H}, J=9.0 \mathrm{~Hz}, \mathrm{Ar}-\mathrm{H}), 7.44-7.34$ (m, 5H, Ar-H), 7.07 (d, 1H, $J=$
$15.5 \mathrm{~Hz}, \mathrm{COCH}=\mathrm{CH}), 7.00(\mathrm{~d}, 2 \mathrm{H}, J=9.0 \mathrm{~Hz}, \mathrm{Ar}-\mathrm{H}), 6.72(\mathrm{~s}, 1 \mathrm{H}$, $\mathrm{H}-4$ ), 5.12 (brs, 2H, $\mathrm{PhCH}_{2}$ ), 4.69 (d, $\left.1 \mathrm{H}, J=6.5 \mathrm{~Hz}, \mathrm{H}-1^{\prime}\right), 4.43-$ 4.38 (m, 2H, H-4'), 4.30-4.27 (m, 1H, H-3'), 3.93 (dd, $1 \mathrm{H}, J=3.0$, $10.5 \mathrm{~Hz}, \mathrm{H}-2^{\prime}$ ), 2.65 (s, 3H, $\left.\mathrm{CH}_{3}\right) ;{ }^{13} \mathrm{C} \mathrm{NMR}$ (125 $\mathrm{MHz}, \mathrm{CDCl}_{3}$ ): $\delta 185.7(C=\mathrm{O}), 160.7(\mathrm{C}-4), 150.2(\mathrm{C}-1), 143.2(\mathrm{COCH}=\mathrm{CH})$, 136.3, 130.1, 128.6 (Ar-C), $128.1(\mathrm{COCH}=\mathrm{CH}), 127.7,127.4(\mathrm{Ar}-$ C), 121.5 (C-2), 115.2 (Ar-C), 109.0 (C-3), 77.2 (C-1'), 74.8 (C-3'), $73.2\left(\mathrm{C}-4^{\prime}\right), 71.0\left(\mathrm{C}-2^{\prime}\right), 70.0\left(\mathrm{PhCH}_{2}\right), 14.6\left(\mathrm{CH}_{3}\right)$; ESI-MS: 443.11 $[\mathrm{M}+\mathrm{Na}]^{+}$; anal. calcd for $\mathrm{C}_{25} \mathrm{H}_{24} \mathrm{O}_{6}$ (420.45): C, 71.41; $\mathrm{H}, 5.75 \%$; found: C, 71.30; H, 5.87\%.

Compound 11. Yellow solid; $R_{\mathrm{f}}: 0.24$ (hexane-EtOAc; $1: 2$ ); $\mathrm{mp} 124-125{ }^{\circ} \mathrm{C}[\mathrm{EtOH}] ;[\alpha]_{\mathrm{D}}^{25}-15\left(c 1.0, \mathrm{CHCl}_{3}\right) ;{ }^{1} \mathrm{H}$ NMR $(500$ $\left.\mathrm{MHz}, \mathrm{CDCl}_{3}\right): \delta 7.56(\mathrm{~d}, 1 \mathrm{H}, J=15.5 \mathrm{~Hz}, \mathrm{COCH}=\mathrm{CH}), 7.43(\mathrm{~d}$, $2 \mathrm{H}, J=8.0 \mathrm{~Hz}, \mathrm{Ar}-\mathrm{H}), 7.28$ (d, $2 \mathrm{H}, J=8.0 \mathrm{~Hz}, \mathrm{Ar}-\mathrm{H}), 7.04$ (d, 1H, $J$ $=15.5 \mathrm{~Hz}, \mathrm{COCH}=\mathrm{CH}), 6.62(\mathrm{~s}, 1 \mathrm{H}, \mathrm{H}-3), 4.58(\mathrm{~d}, 1 \mathrm{H}, J=$ $6.5 \mathrm{~Hz}, \mathrm{H}-1^{\prime}$ ), 4.31-4.27 (m, 2H, H-4'), 4.18-4.15 (m, 1H, H-3'), $3.81\left(\mathrm{dd}, 1 \mathrm{H}, J=2.5,10.0 \mathrm{~Hz}, \mathrm{H}-2^{\prime}\right), 2.54\left(\mathrm{~s}, 3 \mathrm{H}, \mathrm{CH}_{3}\right) ;{ }^{13} \mathrm{C} \mathrm{NMR}$ $\left(125 \mathrm{MHz}, \mathrm{CDCl}_{3}\right): \delta 186.3(C=\mathrm{O}), 161.1(\mathrm{C}-4), 150.0(\mathrm{C}-1), 141.9$ $(\mathrm{COCH}=\mathrm{CH}), 136.2,133.2,129.5,128.4,129.2(\mathrm{Ar}-\mathrm{C}), 124.0$ $(\mathrm{COCH}=\mathrm{CH}), 122.2(\mathrm{C}-2), 108.9(\mathrm{C}-3), 77.1\left(\mathrm{C}-1^{\prime}\right), 74.8\left(\mathrm{C}-3^{\prime}\right)$, $73.1\left(\mathrm{C}-4^{\prime}\right), 71.0\left(\mathrm{C}-2^{\prime}\right), 14.6\left(\mathrm{CH}_{3}\right)$; ESI-MS: $371.0[\mathrm{M}+\mathrm{Na}]^{+}$; anal. calcd for $\mathrm{C}_{18} \mathrm{H}_{17} \mathrm{ClO}_{5}$ (348.78): C, 61.99; $\mathrm{H}, 4.91 \%$; found: $\mathrm{C}$, $61.84 ; \mathrm{H}, 5.02 \%$.

Compound 12. Yellow solid; $R_{\mathrm{f}}: 0.35$ (hexane-EtOAc; $1: 3$ ); $\mathrm{mp} 122-123{ }^{\circ} \mathrm{C}[\mathrm{EtOH}] ;[\alpha]_{\mathrm{D}}^{25}-10\left(c 1.0, \mathrm{CHCl}_{3}\right) ;{ }^{1} \mathrm{H}$ NMR $(500$ $\left.\mathrm{MHz}, \mathrm{CDCl}_{3}\right): \delta 8.54(\mathrm{~d}, 1 \mathrm{H}, J=15.5 \mathrm{~Hz}, \mathrm{COCH}=\mathrm{CH}), 8.21(\mathrm{~d}$, $1 \mathrm{H}, J=8.0 \mathrm{~Hz}, \mathrm{Ar}-\mathrm{H}), 7.86-7.76(\mathrm{~m}, 2 \mathrm{H}, \mathrm{Ar}-\mathrm{H}), 7.55-7.42(\mathrm{~m}, 4 \mathrm{H}$, $\mathrm{Ar}-\mathrm{H}), 7.21(\mathrm{~d}, 1 \mathrm{H}, J=15.5 \mathrm{~Hz}, \mathrm{COCH}=\mathrm{CH}), 6.71(\mathrm{~s}, 1 \mathrm{H}, \mathrm{H}-4)$, 4.67 (d, $\left.1 \mathrm{H}, J=6.0 \mathrm{~Hz}, \mathrm{H}-1^{\prime}\right), 4.35-4.34$ (m, 2H, H-4'), 4.22-4.19 (m, $\left.1 \mathrm{H}, \mathrm{H}-3^{\prime}\right)$, 3.87-3.85 (m, $\left.1 \mathrm{H}, \mathrm{H}-2^{\prime}\right), 2.63\left(\mathrm{~s}, 3 \mathrm{H}, \mathrm{CH}_{3}\right) ;{ }^{13} \mathrm{C}$ NMR (125 MHz, $\left.\mathrm{CDCl}_{3}\right): \delta 185.2(C=\mathrm{O}), 160.0(\mathrm{C}-4), 150.3(\mathrm{C}-1)$, $140.2(\mathrm{COCH}=\mathrm{CH}), 133.7,132.1,131.8,130.7,128.7,127.5$, 126.4, 125.3, 125.1, (Ar-C), $123.5(\mathrm{COCH}=\mathrm{CH}), 122.3(\mathrm{C}-2)$, 108.9 (C-3), 77.1 (C-1'), $74.8\left(\mathrm{C}-3^{\prime}\right), 73.2\left(\mathrm{C}-4^{\prime}\right), 71.0\left(\mathrm{C}-2^{\prime}\right), 14.7$ $\left(\mathrm{CH}_{3}\right)$; ESI-MS: $387.1[\mathrm{M}+\mathrm{Na}]^{+}$; anal. calcd for $\mathrm{C}_{22} \mathrm{H}_{20} \mathrm{O}_{5}$ (364.39): C, 72.51; H, 5.53\%; found: C, 72.42; H, 5.65\%.

Compound 13. Yellow solid; $R_{\mathrm{f}}: 0.15$ (hexane-EtOAc; $1: 1$ ); mp 103-104 ${ }^{\circ} \mathrm{C}[\mathrm{EtOH}] ;[\alpha]_{\mathrm{D}}^{25}-26\left(c\right.$ 1.0, $\left.\mathrm{CHCl}_{3}\right) ;{ }^{1} \mathrm{H}$ NMR (500 $\mathrm{MHz}, \mathrm{CDCl}_{3}$ ): $\delta 7.60$ (d, $\left.1 \mathrm{H}, J=9.0 \mathrm{~Hz}, \mathrm{Ar}-\mathrm{H}\right), 7.58(\mathrm{~d}, 1 \mathrm{H}, J=$ $15.5 \mathrm{~Hz}, \mathrm{COCH}=\mathrm{CH}), 7.18(\mathrm{~d}, 1 \mathrm{H}, J=15.5 \mathrm{~Hz}, \mathrm{COCH}=\mathrm{CH})$, 6.81-6.79 (m, 2H, Ar-H), 6.60 (s, 1H, H-4), 4.77 (d, $1 \mathrm{H}, J=7.0 \mathrm{~Hz}$, H-1' $)$, 4.52-4.46 (m, 2H, H-4' $4^{\prime}$, 4.38-4.35 (m, 1H, H-3'), 4.01-3.98 (m, 1H, H-2'), 2.75 (s, 3H, $\left.\mathrm{CH}_{3}\right) ;{ }^{13} \mathrm{C} \mathrm{NMR} \mathrm{(125} \mathrm{MHz}, \mathrm{CDCl}_{3}$ ): $\delta 185.2(C=\mathrm{O}), 160.0(\mathrm{C}-4), 150.3(\mathrm{C}-1), 144.7(\mathrm{COCH}=\mathrm{CH})$, $129.3(\mathrm{C}-2), 121.2(\mathrm{COCH}=\mathrm{CH}), 116.0,112.6(\mathrm{Ar}-\mathrm{C}), 109.0(\mathrm{C}-3)$, $77.2\left(\mathrm{C}-1^{\prime}\right), 74.7\left(\mathrm{C}-3^{\prime}\right)$, $73.1\left(\mathrm{C}-4^{\prime}\right), 71.0\left(\mathrm{C}-2^{\prime}\right), 14.6\left(\mathrm{CH}_{3}\right)$; ESI-MS: $327.0[\mathrm{M}+\mathrm{Na}]^{+}$; anal. calcd for $\mathrm{C}_{16} \mathrm{H}_{16} \mathrm{O}_{6}$ (304.29): $\mathrm{C}, 63.15 ; \mathrm{H}$, $5.30 \%$; found: $\mathrm{C}, 63.10 ; \mathrm{H}, 5.42 \%$.

Compound 14. Yellow solid; $R_{\mathrm{f}}$ : 0.33 (hexane-EtOAc; $1: 3$ ); mp 93-95 ${ }^{\circ} \mathrm{C}[\mathrm{EtOH}] ;[\alpha]_{\mathrm{D}}^{25}-37\left(c \quad 1.0, \mathrm{CHCl}_{3}\right) ;{ }^{1} \mathrm{H}$ NMR $(500$ $\left.\mathrm{MHz}, \mathrm{CDCl}_{3}\right): \delta 7.76(\mathrm{~d}, 1 \mathrm{H}, J=15.5 \mathrm{~Hz}, \mathrm{COCH}=\mathrm{CH}), 7.58(\mathrm{~d}$, $2 \mathrm{H}, J=9.0 \mathrm{~Hz}, \mathrm{Ar}-\mathrm{H}), 7.05(\mathrm{~d}, 1 \mathrm{H}, J=15.5 \mathrm{~Hz}, \mathrm{COCH}=\mathrm{CH}$ ), 6.78-6.75 (m, 3H, Ar-H), 6.66 (s, 1H, H-4), 4.73 (d, $1 \mathrm{H}, J=7.0 \mathrm{~Hz}$, H-1'), 4.50-4.44 (m, 2H, H-4'), 4.37-4.32 (m, 1H, H-3'), 3.99 (dd, $\left.1 \mathrm{H}, J=3.0,10.0 \mathrm{~Hz}, \mathrm{H}-2^{\prime}\right), 3.15\left(\mathrm{~s}, 6 \mathrm{H}, \mathrm{N}\left(\mathrm{CH}_{3}\right)_{2}\right), 2.46(\mathrm{~s}, 3 \mathrm{H}$, $\left.\mathrm{CH}_{3}\right) ;{ }^{13} \mathrm{C}$ NMR (125 MHz, $\left.\mathrm{CDCl}_{3}\right): \delta 185.7(\mathrm{C}=\mathrm{O}), 159.7(\mathrm{C}-4)$, 149.7 (C-1), 148.6 (Ar-C), 144.7 (COCH = CH), 130.4 (2C, Ar-C), 
$122.6(\mathrm{COCH}=\mathrm{CH}), 121.9(\mathrm{Ar}-\mathrm{C}), 118.5(\mathrm{C}-2), 111.9$ (2C, Ar-C),

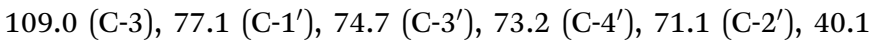
(2C, $\left.\mathrm{N}\left(\mathrm{CH}_{3}\right)_{2}\right), 14.6\left(2 \mathrm{C}, \mathrm{CH}_{3}\right)$; ESI-MS: $380.1[\mathrm{M}+\mathrm{Na}]^{+}$; anal. calcd for $\mathrm{C}_{20} \mathrm{H}_{23} \mathrm{NO}_{5}$ (357.40): C, 67.21; $\mathrm{H}, 6.49 \%$; found: $\mathrm{C}$, $67.14 ; \mathrm{H}, 6.60 \%$.

Compound 15. Yellow solid; $R_{\mathrm{f}}: 0.25$ (hexane-EtOAc; $1: 2$ ); $\mathrm{mp} 102-104{ }^{\circ} \mathrm{C}[\mathrm{EtOH}] ;[\alpha]_{\mathrm{D}}^{25}-20\left(c 1.0, \mathrm{CHCl}_{3}\right) ;{ }^{1} \mathrm{H}$ NMR $(500$ $\left.\mathrm{MHz} \mathrm{CDCl}_{3}\right): \delta 7.80(\mathrm{~d}, 1 \mathrm{H}, J=16.0 \mathrm{~Hz}, \mathrm{COCH}=\mathrm{CH}), 7.69-7.68$ (m, 2H, Ar-H), 7.50-7.48 (m, 3H, Ar-H), 7.27 (d, $1 \mathrm{H}, J=16.0 \mathrm{~Hz}$, $\mathrm{COCH}=\mathrm{CH}), 6.81(\mathrm{~s}, 1 \mathrm{H}, \mathrm{H}-4), 4.78\left(\mathrm{~d}, 1 \mathrm{H}, J=6.5 \mathrm{~Hz}, \mathrm{H}-1^{\prime}\right)$, 4.51-4.47 (m, 2H, H-4') 4.38-4.35 (m, 1H, H-3'), 4.01 (dd, $1 \mathrm{H}, J$ $\left.=3.0,10.0 \mathrm{~Hz}, \mathrm{H}-2^{\prime}\right), 2.73\left(\mathrm{~s}, 3 \mathrm{H}, \mathrm{CH}_{3}\right) ;{ }^{13} \mathrm{C} \mathrm{NMR}(125 \mathrm{MHz}$, $\left.\mathrm{CDCl}_{3}\right): \delta 185.5(C=\mathrm{O}), 159.9(\mathrm{C}-4), 150.0(\mathrm{C}-1), 143.5(\mathrm{COCH}=$ $\mathrm{CH}), 134.7,130.4,128.9,128.4(\mathrm{Ar}-\mathrm{C}), 123.6(\mathrm{COCH}=\mathrm{CH}), 122.3$ (C-2), 109.0 (C-3), $77.2\left(\mathrm{C}-1^{\prime}\right), 74.8\left(\mathrm{C}-3^{\prime}\right), 73.2\left(\mathrm{C}-4^{\prime}\right), 71.0\left(\mathrm{C}-2^{\prime}\right)$, 14.6 $\left(\mathrm{CH}_{3}\right)$; ESI-MS: $337.1[\mathrm{M}+\mathrm{Na}]^{+}$; anal. calcd for $\mathrm{C}_{18} \mathrm{H}_{18} \mathrm{O}_{5}$ (314.33): C, 68.78; H, 5.77\%; found: C, 68.65; H, 5.90\%.

Compound 16. Yellow solid; $R_{\mathrm{f}}: 0.30$ (hexane-EtOAc; $1: 3$ ); $\operatorname{mp} 108-110{ }^{\circ} \mathrm{C}[\mathrm{EtOH}] ;[\alpha]_{\mathrm{D}}^{25}-21\left(c 1.0, \mathrm{CHCl}_{3}\right) ;{ }^{1} \mathrm{H}$ NMR $(500$ $\left.\mathrm{MHz} \mathrm{CDCl}_{3}\right): \delta 13.2(\mathrm{~s}, 1 \mathrm{H}, \mathrm{NH}), 6.76(\mathrm{~d}, 1 \mathrm{H}, J=14.5 \mathrm{~Hz}, \mathrm{COCH}$ $=\mathrm{CH}), 6.75(\mathrm{~d}, 1 \mathrm{H}, J=8.0 \mathrm{~Hz}, \mathrm{Ar}-\mathrm{H}), 6.67(\mathrm{~s}, 1 \mathrm{H}, \mathrm{H}-4), 6.53-6.49$ $(\mathrm{m}, 3 \mathrm{H}, \mathrm{COCH}=\mathrm{CH}, \mathrm{Ar}-\mathrm{H}), 4.77\left(\mathrm{~d}, 1 \mathrm{H}, J=6.5 \mathrm{~Hz}, \mathrm{H}-1^{\prime}\right), 4.48-$ $4.46\left(\mathrm{~m}, 2 \mathrm{H}, \mathrm{H}-4^{\prime}\right), 4.37-4.34\left(\mathrm{~m}, 1 \mathrm{H}, \mathrm{H}-3^{\prime}\right), 3.98(\mathrm{dd}, 1 \mathrm{H}, J=2.5$, $10.5 \mathrm{~Hz}, \mathrm{H}-2^{\prime}$ ), 2.65 (s, 3H, $\left.\mathrm{CH}_{3}\right) ;{ }^{13} \mathrm{C} \mathrm{NMR}\left(125 \mathrm{MHz}, \mathrm{CDCl}_{3}\right.$ ): $\delta 185.2(C=\mathrm{O}), 157.1$ (C-4), 149.0 (C-1), $138.9(\mathrm{C}-2), 128.5$ (COCH $=\mathrm{CH}), 123.9(\mathrm{Ar}-\mathrm{C}), 118.9(\mathrm{COCH}=\mathrm{CH}), 111.4(\mathrm{Ar}-\mathrm{C}), 109.9(\mathrm{C}-$ 3), 107.7, 103.2 (Ar-C), 77.3 (C-1'), $74.6\left(\mathrm{C}-3^{\prime}\right), 73.0$ (C-4'), 71.0 (C$\left.2^{\prime}\right), 14.0\left(\mathrm{CH}_{3}\right)$; ESI-MS: $326.1[\mathrm{M}+\mathrm{Na}]^{+}$; anal. calcd for $\mathrm{C}_{16} \mathrm{H}_{17} \mathrm{NO}_{5}$ (303.31): C, 63.36; H, 5.65\%; found: C, 63.20; H, $5.48 \%$.

Compound 17. Pale yellow solid; $R_{\mathrm{f}}$ : 0.30 (hexane-EtOAc; 2 : 5); mp 145-147 ${ }^{\circ} \mathrm{C}[\mathrm{EtOH}] ;[\alpha]_{\mathrm{D}}^{25}-32\left(c 1.0, \mathrm{CHCl}_{3}\right) ;{ }^{1} \mathrm{H} \mathrm{NMR}$ $\left(500 \mathrm{MHz}, \mathrm{CDCl}_{3}\right): \delta 8.26(\mathrm{~d}, 2 \mathrm{H}, J=6.5 \mathrm{~Hz}, \mathrm{Ar}-\mathrm{H}), 7.75(\mathrm{~d}, 1 \mathrm{H}, J$ $=16.0 \mathrm{~Hz}, \mathrm{COCH}=\mathrm{CH}), 7.73(\mathrm{~d}, 2 \mathrm{H}, J=7.5 \mathrm{~Hz}, \mathrm{Ar}-\mathrm{H}), 7.29(\mathrm{~d}$, $1 \mathrm{H}, J=16.0 \mathrm{~Hz}, \mathrm{COCH}=\mathrm{CH}), 6.76(\mathrm{~s}, 1 \mathrm{H}, \mathrm{H}-3), 4.71(\mathrm{~d}, 1 \mathrm{H}, J=$ $\left.7.0 \mathrm{~Hz}, \mathrm{H}-1^{\prime}\right)$, 4.46-4.41 (m, 2H, H-4'), 4.32-4.22 (m, 1H, H-3'), $3.94\left(\mathrm{dd}, 1 \mathrm{H}, J=3.0,10.0 \mathrm{~Hz}, \mathrm{H}-2^{\prime}\right), 2.65\left(\mathrm{~s}, 3 \mathrm{H}, \mathrm{CH}_{3}\right) ;{ }^{13} \mathrm{C} \mathrm{NMR}$ $\left.\left(125 \mathrm{MHz}^{\mathrm{CDCl}}\right)_{3}\right): \delta 185.7(C=\mathrm{O}), 159.7(\mathrm{C}-4), 142.1(\mathrm{C}-1), 140.1$ $(\mathrm{COCH}=\mathrm{CH}), 132.2,129.6,128.4(\mathrm{Ar}-\mathrm{C}), 127.4(\mathrm{COCH}=\mathrm{CH})$, 124.2 (Ar-C), 123.1 (C-2), 108.8 (C-3), $77.2\left(\right.$ C-1' $\left.^{\prime}\right), 74.8$ (C-3'), 73.3 $\left(\mathrm{C}-4^{\prime}\right)$, $71.0\left(\mathrm{C}-2^{\prime}\right), 14.7\left(\mathrm{CH}_{3}\right)$; ESI-MS: $382.1[\mathrm{M}+\mathrm{Na}]^{+}$; anal. calcd for $\mathrm{C}_{18} \mathrm{H}_{17} \mathrm{NO}_{7}$ (359.33): C, 60.17; $\mathrm{H}, 4.77 \%$; found: $\mathrm{C}$, $60.00 ; \mathrm{H}, 4.95 \%$.

Compound 18. Yellow solid; $R_{\mathrm{f}}: 0.28$ (hexane-EtOAc; $1: 2$ ); mp 133-135 ${ }^{\circ} \mathrm{C}[\mathrm{EtOH}] ;[\alpha]_{\mathrm{D}}^{25}-35\left(c\right.$ 1.0, $\left.\mathrm{CHCl}_{3}\right) ;{ }^{1} \mathrm{H}$ NMR $(500$ $\left.\mathrm{MHz} \mathrm{CDCl}_{3}\right): \delta 7.59(\mathrm{~d}, 1 \mathrm{H}, J=16.5 \mathrm{~Hz}, \mathrm{COCH}=\mathrm{CH}), 7.45(\mathrm{~d}$, $2 \mathrm{H}, J=8.5 \mathrm{~Hz}, \mathrm{Ar}-\mathrm{H}), 6.95(\mathrm{~d}, 1 \mathrm{H}, J=15.5 \mathrm{~Hz}, \mathrm{COCH}=\mathrm{CH}), 6.82$ $(\mathrm{d}, 2 \mathrm{H}, J=8.0 \mathrm{~Hz}, \mathrm{Ar}-\mathrm{H}), 6.61$ (s, $1 \mathrm{H}, \mathrm{H}-3), 4.59$ (d, $1 \mathrm{H}, J=6.5 \mathrm{~Hz}$, $\mathrm{H}-1^{\prime}$ ), 4.32-4.28 (m, 2H, H-4'), 4.19 (dd, $1 \mathrm{H}, J=4.5,10.0 \mathrm{~Hz}, \mathrm{H}^{-}$ $3^{\prime}$ ), $3.82\left(\mathrm{dd}, 1 \mathrm{H}, J=3.0,10.0 \mathrm{~Hz}, \mathrm{H}-2^{\prime}\right), 3.75\left(\mathrm{~s}, 3 \mathrm{H}, \mathrm{CH}_{3}\right), 2.53$ (s, $\left.3 \mathrm{H}, \mathrm{CH}_{3}\right) ;{ }^{13} \mathrm{C}$ NMR $\left(125 \mathrm{MHz}, \mathrm{CDCl}_{3}\right): \delta 185.2(\mathrm{C}=\mathrm{O}), 161.2(\mathrm{Ar}-$ C), 159.0(C-4), $151.1(\mathrm{C}-1), 143.3(\mathrm{COCH}=\mathrm{CH}), 130.1,127.4(\mathrm{Ar}-$ C), $123.5(\mathrm{C}-2), 121.4(\mathrm{COCH}=\mathrm{CH}), 114.4(\mathrm{Ar}-\mathrm{C}), 109.1(\mathrm{C}-3)$, $77.2\left(\mathrm{C}-1^{\prime}\right), 74.7\left(\mathrm{C}-3^{\prime}\right), 73.2\left(\mathrm{C}-4^{\prime}\right), 71.0\left(\mathrm{C}-2^{\prime}\right), 55.3\left(\mathrm{OCH}_{3}\right)$, 14.7 $\left(\mathrm{CH}_{3}\right)$; ESI-MS: $367.1[\mathrm{M}+\mathrm{Na}]^{+}$; anal. calcd for $\mathrm{C}_{19} \mathrm{H}_{20} \mathrm{O}_{6}$ (344.36): C, 66.27; H, 5.85\%; found: C, 66.07; H, 6.00\%.
Compound 19. Yellow solid; $R_{\mathrm{f}}$ : 0.32 (hexane-EtOAc; $1: 3$ ); $\mathrm{mp} 138-140{ }^{\circ} \mathrm{C}[\mathrm{EtOH}] ;[\alpha]_{\mathrm{D}}^{25}-31$ (c 1.0, $\left.\mathrm{CHCl}_{3}\right) ;{ }^{1} \mathrm{H}$ NMR (500 $\left.\mathrm{MHz} \mathrm{CDCl}_{3}\right): \delta 7.57(\mathrm{~d}, 1 \mathrm{H}, J=15.5 \mathrm{~Hz}, \mathrm{COCH}=\mathrm{CH}), 7.43(\mathrm{~d}$, $2 \mathrm{H}, J=8.5 \mathrm{~Hz}, \mathrm{Ar}-\mathrm{H}), 6.93(\mathrm{~d}, 1 \mathrm{H}, J=15.5 \mathrm{~Hz}, \mathrm{COCH}=\mathrm{CH}), 6.70$ $(\mathrm{d}, 2 \mathrm{H}, J=8.0 \mathrm{~Hz}, \mathrm{Ar}-\mathrm{H}), 6.60(\mathrm{~s}, 1 \mathrm{H}, \mathrm{H}-3), 4.58(\mathrm{~d}, 1 \mathrm{H}, J=6.0 \mathrm{~Hz}$, $\mathrm{H}-1^{\prime}$ ), 4.32-4.27 (m, 2H, H-4') 4.17-4.15 (dd, $1 \mathrm{H}, J=4.5$, $10.0 \mathrm{~Hz}, \mathrm{H}-3^{\prime}$ ), 3.99 (q, $2 \mathrm{H}, J=7.0 \mathrm{~Hz}$ each, $\mathrm{OCH}_{2} \mathrm{CH}_{3}$ ), 3.81 (dd, $\left.1 \mathrm{H}, J=3.0,10.0 \mathrm{~Hz}, \mathrm{H}-2^{\prime}\right), 2.52\left(\mathrm{~s}, 3 \mathrm{H}, \mathrm{CH}_{3}\right), 1.36(\mathrm{t}, 3 \mathrm{H}, J=$ $\left.7.0 \mathrm{~Hz}, \mathrm{OCH}_{2} \mathrm{CH}_{3}\right) ;{ }^{13} \mathrm{C} \mathrm{NMR}\left(125 \mathrm{MHz}, \mathrm{CDCl}_{3}\right): \delta 185.7(\mathrm{C}=\mathrm{O})$, 161.0 (Ar-C), 159.6 (C-4), $149.8(\mathrm{C}-1), 143.5(\mathrm{COCH}=\mathrm{CH}), 130.2$, 127.2 (Ar-C), $122.4(\mathrm{C}-2), 121.2(\mathrm{COCH}=\mathrm{CH}), 114.8(\mathrm{Ar}-\mathrm{C}), 109.1$ (C-3), 77.1 (C-1'), $74.7\left(\mathrm{C}-3^{\prime}\right), 73.1\left(\mathrm{C}-4^{\prime}\right), 71.0\left(\mathrm{C}-2^{\prime}\right), 63.5$ $\left(\mathrm{OCH}_{2} \mathrm{CH}_{3}\right), 14.7\left(\mathrm{CH}_{3}\right), 14.6\left(\mathrm{OCH}_{2} \mathrm{CH}_{3}\right)$; ESI-MS: $381.1[\mathrm{M}+$ $\mathrm{Na}]^{+}$; anal. calcd for $\mathrm{C}_{20} \mathrm{H}_{22} \mathrm{O}_{6}$ (358.39): C, 67.03; H, 6.19\%; found: C, 66.90; H, 6.27\%.

Compound 20. Yellow solid; $R_{\mathrm{f}}: 0.24$ (hexane-EtOAc; $1: 2$ ); $\mathrm{mp} 125-127{ }^{\circ} \mathrm{C}[\mathrm{EtOH}] ;[\alpha]_{\mathrm{D}}^{25}-40\left(c\right.$ 1.0, $\left.\mathrm{CHCl}_{3}\right) ;{ }^{1} \mathrm{H}$ NMR $(500$ $\left.\mathrm{MHz}, \mathrm{CDCl}_{3}\right): \delta 7.56(\mathrm{~d}, 1 \mathrm{H}, J=16.0 \mathrm{~Hz}, \mathrm{COCH}=\mathrm{CH}), 7.21-7.15$ $(\mathrm{m}, 1 \mathrm{H}, \mathrm{Ar}-\mathrm{H}), 7.07-6.98(\mathrm{~m}, 3 \mathrm{H}, \mathrm{COCH}=\mathrm{CH}, \mathrm{Ar}-\mathrm{H}), 6.83(\mathrm{~d}, 1 \mathrm{H}$, $J=8.0 \mathrm{~Hz}, \mathrm{Ar}-\mathrm{H}), 6.62$ (s, $1 \mathrm{H}, \mathrm{H}-3), 4.58$ (d, $1 \mathrm{H}, J=6.5 \mathrm{~Hz}, \mathrm{H}_{-1}^{\prime}$ ), 4.28-4.26 (m, 2H, H-4'), 4.16-4.12 (m, 1H, H-3'), 3.80-3.73 (m, $\left.4 \mathrm{H}, \mathrm{OCH}_{3}, \mathrm{H}-2^{\prime}\right), 2.50\left(\mathrm{~s}, 3 \mathrm{H}, \mathrm{CH}_{3}\right) ;{ }^{13} \mathrm{C} \mathrm{NMR}\left(125 \mathrm{MHz}, \mathrm{CDCl}_{3}\right)$ : $\delta 185.7(C=\mathrm{O}), 159.9$ (Ar-C), 159.9 (C-4), 150.0 (C-1), 143.5 $(\mathrm{COCH}=\mathrm{CH}), 136.0,129.9,123.9(\mathrm{Ar}-\mathrm{C}), 122.2(\mathrm{C}-2), 121.0$ $(\mathrm{COCH}=\mathrm{CH}), 116.2,113.4(\mathrm{Ar}-\mathrm{C}), 109.1(\mathrm{C}-3), 77.1\left(\mathrm{C}-1^{\prime}\right), 74.8$ $\left(\mathrm{C}-3^{\prime}\right), 73.1\left(\mathrm{C}-4^{\prime}\right), 71.0\left(\mathrm{C}-2^{\prime}\right), 55.2\left(\mathrm{OCH}_{3}\right), 14.6\left(\mathrm{CH}_{3}\right)$; ESI-MS: $367.1[\mathrm{M}+\mathrm{Na}]^{+}$; anal. calcd for $\mathrm{C}_{19} \mathrm{H}_{20} \mathrm{O}_{6}$ (344.36): C, 66.27; $\mathrm{H}$, $5.85 \%$; found: C, 66.10; $\mathrm{H}, 5.99 \%$.

Compound 21. Yellow solid; $R_{\mathrm{f}}: 0.27$ (hexane-EtOAc; $1: 2$ ); mp 155-157 ${ }^{\circ} \mathrm{C}[\mathrm{EtOH}] ;[\alpha]_{\mathrm{D}}^{25}-16$ (c 1.0, $\left.\mathrm{CHCl}_{3}\right) ;{ }^{1} \mathrm{H}$ NMR (500 $\left.\mathrm{MHz} \mathrm{CDCl}_{3}\right): \delta 8.12(\mathrm{~d}, 1 \mathrm{H}, J=16.0 \mathrm{~Hz}, \mathrm{COCH}=\mathrm{CH}), 7.69(\mathrm{dd}$, $1 \mathrm{H}, J=2.0,7.0 \mathrm{~Hz}, \mathrm{Ar}-\mathrm{H}), 7.44$ (dd, $1 \mathrm{H}, J=1.0,7.5 \mathrm{~Hz}, \mathrm{Ar}-\mathrm{H}$ ), 7.34-7.24 (m, 2H, Ar-H), $7.16(\mathrm{~d}, 1 \mathrm{H}, J=16.0 \mathrm{~Hz}, \mathrm{COCH}=$ $\mathrm{CH}$ ), 6.74 (s, 1H, H-3), 4.71 (d, 1H, $\left.J=6.5 \mathrm{~Hz}, \mathrm{H}-1^{\prime}\right), 4.45-4.39$ (m, 2H, H-4'), 4.30-4.27 (m, 1H, H-3'), 3.92 (dd, $1 \mathrm{H}, J=3.0$, $10.0 \mathrm{~Hz}, \mathrm{H}-2^{\prime}$ ), 2.65 (s, 3H, $\mathrm{CH}_{3}$ ); ${ }^{13} \mathrm{C} \mathrm{NMR} \mathrm{(125} \mathrm{MHz}, \mathrm{CDCl}_{3}$ ): $\delta 186.2(C=\mathrm{O}), 160.3(\mathrm{C}-4), 149.9(\mathrm{C}-1), 139.3(\mathrm{COCH}=\mathrm{CH})$, 135.5, 133.1, 131.1, 130.3, 127.7, 127.0 (Ar-C), $126.4(\mathrm{COCH}=$ CH), 122.1 (C-2), 109.1 (C-3), 77.2 (C-1'), 74.8 (C-3'), 73.3 (C-4'), $71.0\left(\mathrm{C}-2^{\prime}\right), 14.7\left(\mathrm{CH}_{3}\right)$; ESI-MS: $371.0[\mathrm{M}+\mathrm{Na}]^{+}$; anal. calcd for $\mathrm{C}_{18} \mathrm{H}_{17} \mathrm{ClO}_{5}$ (348.78): C, 61.99; H, 4.91\%; found: C, 61.82; H, $5.05 \%$.

Compound 22. Yellow solid; $R_{\mathrm{f}}$ : 0.18 (hexane-EtOAc; $1: 2$ ); $\mathrm{mp} 121-123{ }^{\circ} \mathrm{C}[\mathrm{EtOH}] ;[\alpha]_{\mathrm{D}}^{25}-18\left(c 1.0, \mathrm{CHCl}_{3}\right) ;{ }^{1} \mathrm{H}$ NMR (500 $\left.\mathrm{MHz}, \mathrm{CDCl}_{3}\right): \delta 7.61-7.39(\mathrm{~m}, 5 \mathrm{H}, J=16.0 \mathrm{~Hz}, \mathrm{COCH}=\mathrm{CH}, \mathrm{Ar}-$ $\mathrm{H}), 7.13(\mathrm{~d}, 1 \mathrm{H}, J=15.5 \mathrm{~Hz}, \mathrm{COCH}=\mathrm{CH}), 6.64(\mathrm{~s}, 1 \mathrm{H}, \mathrm{H}-3), 4.59$ $\left(\mathrm{d}, 1 \mathrm{H}, J=6.5 \mathrm{~Hz}, \mathrm{H}-1^{\prime}\right)$, 4.31-4.27 (m, 2H, H-4'), 4.18-4.15 (m, $\left.1 \mathrm{H}, \mathrm{H}-3^{\prime}\right), 3.81\left(\mathrm{dd}, 1 \mathrm{H}, J=3.0,9.0 \mathrm{~Hz}, \mathrm{H}-2^{\prime}\right), 2.54\left(\mathrm{~s}, 3 \mathrm{H}, \mathrm{CH}_{3}\right.$ ); ${ }^{13} \mathrm{C}$ NMR (125 MHz, $\left.\mathrm{CDCl}_{3}\right): \delta 185.0(C=\mathrm{O}), 160.3(\mathrm{C}-4), 150.2$ (C-1), $141.4(\mathrm{COCH}=\mathrm{CH}), 138.1,128.4,126.9,125.8$ (Ar-C), $125.8(\mathrm{COCH}=\mathrm{CH}), 122.2(\mathrm{C}-2), 108.9(\mathrm{C}-3), 77.1\left(\mathrm{C}-1^{\prime}\right), 74.8$ $\left(\mathrm{C}-3^{\prime}\right), 73.2\left(\mathrm{C}-4^{\prime}\right), 71.0\left(\mathrm{C}-2^{\prime}\right), 14.7\left(\mathrm{CH}_{3}\right)$; ESI-MS: $405.1[\mathrm{M}+$ $\mathrm{Na}]^{+}$; anal. calcd for $\mathrm{C}_{19} \mathrm{H}_{17} \mathrm{~F}_{3} \mathrm{O}_{5}$ (382.33): C, 59.69; $\mathrm{H}, 4.48 \%$; found: $\mathrm{C}, 59.58 ; \mathrm{H}, 4.60 \%$.

Compound 23. Yellow solid; $R_{\mathrm{f}}: 0.27$ (hexane-EtOAc; $1: 2$ ); mp 167-169 ${ }^{\circ} \mathrm{C}[\mathrm{EtOH}] ;[\alpha]_{\mathrm{D}}^{25}-29\left(c\right.$ 1.0, $\left.\mathrm{CHCl}_{3}\right) ;{ }^{1} \mathrm{H}$ NMR $(500$ 
$\left.\mathrm{MHz}, \mathrm{CDCl}_{3}\right): \delta 8.35(\mathrm{~s}, 1 \mathrm{H}, \mathrm{Ar}-\mathrm{H}), 8.12(\mathrm{~d}, 1 \mathrm{H}, J=8.5 \mathrm{~Hz}, \mathrm{Ar}-\mathrm{H})$, $7.76(\mathrm{~d}, 1 \mathrm{H}, J=7.5 \mathrm{~Hz}, \mathrm{Ar}-\mathrm{H}), 7.61$ (d, $1 \mathrm{H}, J=15.5 \mathrm{~Hz}, \mathrm{COCH}=$ $\mathrm{CH}), 7.50$ (t, $1 \mathrm{H}, J=8.0 \mathrm{~Hz}$ each, Ar-H), 7.19 (d, $1 \mathrm{H}, J=15.5 \mathrm{~Hz}$, $\mathrm{COCH}=\mathrm{CH}), 6.67(\mathrm{~s}, 1 \mathrm{H}, \mathrm{H}-3), 4.60\left(\mathrm{~d}, 1 \mathrm{H}, J=6.5 \mathrm{~Hz}, \mathrm{H}-1^{\prime}\right)$, 4.31-4.28 (m, 2H, H-4'), 4.18-4.15 (m, 1H, H-3'), 3.82 (dd, $1 \mathrm{H}, J$ $\left.=2.5,10.5 \mathrm{~Hz}, \mathrm{H}-2^{\prime}\right), 2.54\left(\mathrm{~s}, 3 \mathrm{H}, \mathrm{CH}_{3}\right) ;{ }^{13} \mathrm{C} \mathrm{NMR}(125 \mathrm{MHz}$, $\left.\mathrm{CDCl}_{3}\right): \delta 184.6(C=\mathrm{O}), 160.6(\mathrm{C}-4), 150.3(\mathrm{C}-1), 148.7$ (Ar-C), $140.2(\mathrm{COCH}=\mathrm{CH}), 136.5,134.3,129.9,126.2,124.5(\mathrm{Ar}-\mathrm{C})$, $122.2(\mathrm{COCH}=\mathrm{CH}), 122.0(\mathrm{C}-2), 108.8(\mathrm{C}-3), 77.0\left(\mathrm{C}-1^{\prime}\right), 74.8$ $\left(\mathrm{C}-3^{\prime}\right), 73.2\left(\mathrm{C}^{\prime} 4^{\prime}\right), 71.0\left(\mathrm{C}-2^{\prime}\right), 14.7\left(\mathrm{CH}_{3}\right)$; ESI-MS: $382.1[\mathrm{M}+$ $\mathrm{Na}]^{+}$; anal. calcd for $\mathrm{C}_{18} \mathrm{H}_{17} \mathrm{NO}_{7}$ (359.33): C, 60.17; $\mathrm{H}, 4.77 \%$; found: $\mathrm{C}, 60.05 ; \mathrm{H}, 4.95 \%$.

Compound 24. Yellow solid; $R_{\mathrm{f}}: 0.33$ (hexane-EtOAc; $1: 2$ ); $\mathrm{mp} 98-100{ }^{\circ} \mathrm{C}[\mathrm{EtOH}] ;[\alpha]_{\mathrm{D}}^{25}-21$ (c 1.0, $\left.\mathrm{CHCl}_{3}\right) ;{ }^{1} \mathrm{H}$ NMR $(500$ $\left.\mathrm{MHz} \mathrm{CDCl}_{3}\right): \delta 7.59(\mathrm{~d}, 1 \mathrm{H}, J=15.5 \mathrm{~Hz}, \mathrm{COCH}=\mathrm{CH}), 7.46-7.12$ (m, 5H, Ar-H), 7.15-7.12 (m, 2H, Ar-H), 6.91 (d, $1 \mathrm{H}, J=15.5 \mathrm{~Hz}$, $\mathrm{COCH}=\mathrm{CH}), 6.86(\mathrm{~d}, 2 \mathrm{H}, J=8.5 \mathrm{~Hz}, \mathrm{Ar}-\mathrm{H}), 6.66(\mathrm{~s}, 1 \mathrm{H}, \mathrm{H}-4)$, 5.16 (br s, $2 \mathrm{H}, \mathrm{PhCH}_{2}$ ), 4.67 (d, $\left.1 \mathrm{H}, J=6.0 \mathrm{~Hz}, \mathrm{H}-1^{\prime}\right), 4.37-$ 4.35 (m, 2H, H-4'), 4.25-4.23 (m, 1H, H-3'), 3.90-3.88 (m, 4H, H$\left.2^{\prime}, \mathrm{OCH}_{3}\right), 2.58\left(\mathrm{~s}, 3 \mathrm{H}, \mathrm{CH}_{3}\right) ;{ }^{13} \mathrm{C} \mathrm{NMR}\left(125 \mathrm{MHz}, \mathrm{CDCl}_{3}\right): \delta 185.7$ $(C=\mathrm{O}), 159.6(\mathrm{C}-4), 152.1(\mathrm{C}-1), 150.0,148.3(\mathrm{Ar}-\mathrm{C}), 143.2(\mathrm{COCH}$ $=\mathrm{CH}), 136.7,128.6,128.0,127.5,127.3,(\mathrm{Ar}-\mathrm{C}), 123.3(\mathrm{COCH}=$ $\mathrm{CH}$ ), 122.4 (Ar-C), 121.5 (C-2), 113.1, 111.5 (Ar-C), 109.1 (C-3), $77.1\left(\mathrm{C}-1^{\prime}\right), 74.7\left(\mathrm{C}-3^{\prime}\right), 73.2\left(\mathrm{C}-4^{\prime}\right), 71.2\left(\mathrm{PhCH}_{2}\right), 71.0\left(\mathrm{C}-2^{\prime}\right)$, $55.9\left(\mathrm{OCH}_{3}\right), 14.6\left(\mathrm{CH}_{3}\right)$; ESI-MS: $473.1[\mathrm{M}+\mathrm{Na}]^{+}$; anal. calcd for $\mathrm{C}_{26} \mathrm{H}_{26} \mathrm{O}_{7}$ (450.48): C, 69.32; H, 5.82\%; found: C, 69.18; H, $6.00 \%$.

Compound 25. White solid; $R_{\mathrm{f}}: 0.40$ (hexane-EtOAc; $1: 1$ ); mp 113-115 ${ }^{\circ} \mathrm{C}[\mathrm{EtOH}] ;[\alpha]_{\mathrm{D}}^{25}-68$ (c 1.0, $\left.\mathrm{CHCl}_{3}\right) ;{ }^{1} \mathrm{H}$ NMR (500 $\mathrm{MHz}_{\mathrm{CDCl}}$ ): $\delta 8.57(\mathrm{~s}, 1 \mathrm{H}, \mathrm{Ar}-\mathrm{H}), 8.36(\mathrm{dd}, 1 \mathrm{H}, J=1.5,8.5 \mathrm{~Hz}$, Ar-H), 7.99 (d, 1H, $J=7.5 \mathrm{~Hz}, \mathrm{Ar}-\mathrm{H}), 7.86$ (d, $1 \mathrm{H}, J=15.5 \mathrm{~Hz}$, $\mathrm{COCH}=\mathrm{CH}), 7.73(\mathrm{t}, 1 \mathrm{H}, J=8.0 \mathrm{~Hz}$ each, Ar-H), $7.39(\mathrm{~d}, 1 \mathrm{H}, J=$ $15.5 \mathrm{~Hz}, \mathrm{COCH}=\mathrm{CH}), 6.88(\mathrm{~s}, 1 \mathrm{H}, \mathrm{H}-3), 5.64-5.58\left(\mathrm{~m}, 2 \mathrm{H}, \mathrm{H}-3^{\prime}\right.$, $\left.\mathrm{H}-2^{\prime}\right), 5.03\left(\mathrm{~d}, 1 \mathrm{H}, J=6.5 \mathrm{~Hz}, \mathrm{H}-1^{\prime}\right), 4.51(\mathrm{dd}, 1 \mathrm{H}, J=5.0,10.5 \mathrm{~Hz}$, $\mathrm{H}-4_{\mathrm{a}}^{\prime}$ ), 4.09 (dd, $1 \mathrm{H}, J=3.5,10.5 \mathrm{~Hz}, \mathrm{H}-4_{\mathrm{b}}^{\prime}$ ), $2.79\left(\mathrm{~s}, 3 \mathrm{H}, \mathrm{CH}_{3}\right)$, 2.24, $2.22\left(2 \mathrm{~s}, 6 \mathrm{H}, \mathrm{CH}_{3} \mathrm{CO}\right) ;{ }^{13} \mathrm{C} \mathrm{NMR}\left(125 \mathrm{MHz}, \mathrm{CDCl}_{3}\right): \delta 184.3$ $(C=\mathrm{O}), 169.7,169.5\left(\mathrm{CH}_{3} \mathrm{CO}\right), 160.9$ (C-4), 148.8 (C-1), 148.7 (Ar$\mathrm{C}), 140.2(\mathrm{COCH}=\mathrm{CH}), 136.6,134.1,129.9,126.2,124.5(\mathrm{Ar}-\mathrm{C})$, $122.2(\mathrm{COCH}=\mathrm{CH}), 122.0(\mathrm{C}-2), 109.2(\mathrm{C}-3), 74.9\left(\mathrm{C}-1^{\prime}\right), 73.7(\mathrm{C}-$ $\left.3^{\prime}\right)$, $71.2\left(\mathrm{C}-2^{\prime}\right), 70.7\left(\mathrm{C}-4^{\prime}\right), 20.6,20.5\left(\mathrm{CH}_{3} \mathrm{CO}\right), 14.7\left(\mathrm{CH}_{3}\right)$; ESIMS: $466.1[\mathrm{M}+\mathrm{Na}]^{+}$; anal. calcd for $\mathrm{C}_{22} \mathrm{H}_{21} \mathrm{NO}_{9}$ (443.40): C, 59.59; H, 4.77\%; found: C, 59.47; H, 4.88\%.

Compound 26. Yellow oil; $R_{\mathrm{f}}: 0.25$ (hexane-EtOAc; $2: 1$ ); $[\alpha]_{\mathrm{D}}^{25}-20\left(c 1.0, \mathrm{CHCl}_{3}\right) ;{ }^{1} \mathrm{H}$ NMR $\left(500 \mathrm{MHz}, \mathrm{CDCl}_{3}\right): \delta 7.73(\mathrm{~d}$, $1 \mathrm{H}, J=15.5 \mathrm{~Hz}, \mathrm{COCH}=\mathrm{CH}), 7.58(\mathrm{~d}, 2 \mathrm{H}, J=7.0 \mathrm{~Hz}, \mathrm{Ar}-\mathrm{H}), 7.51$ $(\mathrm{t}, 2 \mathrm{H}, J=7.5 \mathrm{~Hz}$ each, Ar-H), $7.44(\mathrm{~d}, 1 \mathrm{H}, J=7.0 \mathrm{~Hz}, \mathrm{Ar}-\mathrm{H}), 7.30$ (dd, $1 \mathrm{H}, J=1.5,8.0 \mathrm{~Hz}, \mathrm{Ar}-\mathrm{H}), 7.24$ (d, $1 \mathrm{H}, J=1.5 \mathrm{~Hz}, \mathrm{Ar}-\mathrm{H}), 7.04$ $(\mathrm{d}, 1 \mathrm{H}, J=15.5 \mathrm{~Hz}, \mathrm{COCH}=\mathrm{CH}), 7.01(\mathrm{~d}, 1 \mathrm{H}, J=8.5 \mathrm{~Hz}, \mathrm{Ar}-\mathrm{H})$, 6.81 (s, $1 \mathrm{H}, \mathrm{H}-4), 5.63-5.58\left(\mathrm{~m}, 2 \mathrm{H}, \mathrm{H}-2^{\prime}, \mathrm{H}-3^{\prime}\right), 5.30$ (brs, $2 \mathrm{H}$, $\mathrm{PhCH}_{2}$ ), 5.02 (d, $1 \mathrm{H}, J=6.5 \mathrm{~Hz}, \mathrm{H}-1^{\prime}$ ), 4.50 (dd, $1 \mathrm{H}, J=5.0$, $10.0 \mathrm{~Hz}, \mathrm{H}-4^{\prime}$ ), 4.08 (dd, $\left.1 \mathrm{H}, J=3.5,10.0 \mathrm{~Hz}, \mathrm{H}-4^{\prime}\right), 4.04$ (s, 3H, $\left.\mathrm{OCH}_{3}\right), 2.74\left(\mathrm{~s}, 3 \mathrm{H}, \mathrm{CH}_{3}\right), 2.24,2.19\left(2 \mathrm{~s}, 6 \mathrm{H}, \mathrm{CH}_{3} \mathrm{CO}\right) ;{ }^{13} \mathrm{C} \mathrm{NMR}$ $\left(125 \mathrm{MHz}, \mathrm{CDCl}_{3}\right): \delta 185.4(C=\mathrm{O}), 169.7,169.5\left(2 \mathrm{C}, \mathrm{CH}_{3} C \mathrm{O}\right)$, 159.8 (C-4), 152.2 (C-1), $148.3(\mathrm{Ar}-\mathrm{C}), 143.2(\mathrm{COCH}=\mathrm{CH}), 136.7$, 128.6, 128.0, 127.6, 127.3, (Ar-C), $123.4(\mathrm{COCH}=\mathrm{CH}), 122.5(\mathrm{C}-$ 2), 121.6, 113.1, 111.5 (Ar-C), 109.5 (C-3), 74.9 (C-1'), 73.7 (C-2'), $71.3\left(\mathrm{C}-3^{\prime}\right), 71.1\left(\mathrm{C}-4^{\prime}\right), 70.7\left(\mathrm{PhCH}_{2}\right), 55.9\left(\mathrm{OCH}_{3}\right), 20.6,20.5(2 \mathrm{C}$,
$\left.\mathrm{CH}_{3} \mathrm{CO}\right)$, $14.6\left(\mathrm{CH}_{3}\right)$; ESI-MS: $557.1[\mathrm{M}+\mathrm{Na}]^{+}$; anal. calcd for $\mathrm{C}_{30} \mathrm{H}_{30} \mathrm{O}_{9}$ (534.55): C, 67.41; H, 5.66\%; found: C, 67.30; H, $5.80 \%$

Compound 27. Yellow solid; $R_{\mathrm{f}}: 0.26$ (hexane-EtOAc; $1: 3$ ); mp 123-125 ${ }^{\circ} \mathrm{C}[\mathrm{EtOH}] ;[\alpha]_{\mathrm{D}}^{25}+17$ (c 1.0, $\left.\mathrm{CHCl}_{3}\right) ;{ }^{1} \mathrm{H}$ NMR (500 $\left.\mathrm{MHz}, \mathrm{CDCl}_{3}\right): \delta 8.46$ (s, $\left.1 \mathrm{H}, \mathrm{Ar}-\mathrm{H}\right), 8.25(\mathrm{~d}, 1 \mathrm{H}, J=7.5 \mathrm{~Hz}, \mathrm{Ar}-\mathrm{H})$, $7.89(\mathrm{~d}, 1 \mathrm{H}, J=8.0 \mathrm{~Hz}, \mathrm{Ar}-\mathrm{H}), 7.76(\mathrm{~d}, 1 \mathrm{H}, J=15.5 \mathrm{~Hz}, \mathrm{COCH}=$ $\mathrm{CH}), 7.62(\mathrm{t}, 1 \mathrm{H}, J=8.0 \mathrm{~Hz}$ each, $\mathrm{Ar}-\mathrm{H}), 7.32(\mathrm{~d}, 1 \mathrm{H}, J=15.5 \mathrm{~Hz}$, $\mathrm{COCH}=\mathrm{CH}$ ), 6.87 (s, $1 \mathrm{H}, \mathrm{H}-3), 5.15\left(\mathrm{~d}, 1 \mathrm{H}, J=3.0 \mathrm{~Hz}, \mathrm{H}-1^{\prime}\right)$, 4.50 (brs, $1 \mathrm{H}, \mathrm{H}^{2} 2^{\prime}$ ), $4.42-4.38\left(\mathrm{~m}, 1 \mathrm{H}, \mathrm{H}-4_{\mathrm{a}}^{\prime}\right.$ ), 4.26 (brs, $1 \mathrm{H}, \mathrm{H}-$ $\left.4^{\prime}{ }_{\mathrm{b}}\right), 3.87\left(\mathrm{~d}, 1 \mathrm{H}, J=10.0 \mathrm{~Hz}, \mathrm{H}-2^{\prime}\right), 2.67\left(\mathrm{~s}, 3 \mathrm{H}, \mathrm{CH}_{3}\right) ;{ }^{13} \mathrm{C} \mathrm{NMR}$ $\left(125 \mathrm{MHz}, \mathrm{CDCl}_{3}\right): \delta 184.7(C=\mathrm{O}), 160.5(\mathrm{C}-4), 148.7(\mathrm{C}-1), 148.4$ $(\mathrm{Ar}-\mathrm{C}), 140.3(\mathrm{COCH}=\mathrm{CH}), 136.5,134.2,123.0,126.3,124.6(\mathrm{Ar}-$ $\mathrm{C}), 122.3(\mathrm{COCH}=\mathrm{CH}), 122.1(\mathrm{C}-2), 109.2(\mathrm{C}-3), 78.0\left(\mathrm{C}-1^{\prime}\right), 77.2$ $\left(\mathrm{C}-2^{\prime}\right), 76.8\left(\mathrm{C}-3^{\prime}\right), 73.9\left(\mathrm{C}-4^{\prime}\right), 14.6\left(\mathrm{CH}_{3}\right)$; ESI-MS: $382.1[\mathrm{M}+$ $\mathrm{Na}]^{+}$; anal. calcd for $\mathrm{C}_{18} \mathrm{H}_{17} \mathrm{NO}_{7}$ (359.33): C, 60.17; H, 4.77\%; found: $\mathrm{C}, 60.05$; $\mathrm{H}, 4.95 \%$.

Compound 28. Yellow solid; $R_{\mathrm{f}}$ : 0.18 (hexane-EtOAc; $1: 1$ ); $\mathrm{mp} 131-133{ }^{\circ} \mathrm{C}[\mathrm{EtOH}] ;[\alpha]_{\mathrm{D}}^{25}+12$ (c 1.0, $\left.\mathrm{CHCl}_{3}\right) ;{ }^{1} \mathrm{H}$ NMR $(500$ $\left.\mathrm{MHz}, \mathrm{CDCl}_{3}\right): \delta 7.70(\mathrm{~d}, 1 \mathrm{H}, J=15.5 \mathrm{~Hz}, \mathrm{COCH}=\mathrm{CH}), 7.59-7.41$ (m, 5H, Ar-H), 7.27 (d, 1H, $J=8.0 \mathrm{~Hz}, \mathrm{Ar}-\mathrm{H}), 7.23$ (d, $1 \mathrm{H}, J=$ $1.5 \mathrm{~Hz}, \mathrm{Ar}-\mathrm{H}), 7.05$ (d, $1 \mathrm{H}, J=15.0 \mathrm{~Hz}, \mathrm{COCH}=\mathrm{CH}), 6.98(\mathrm{~d}, 1 \mathrm{H}$, $J=8.5 \mathrm{~Hz}, \mathrm{Ar}-\mathrm{H}$ ), 6.78 (s, 1H, H-3), 5.28 (brs, 2H, $\mathrm{PhCH}_{2}$ ), 4.78 (d, $\left.1 \mathrm{H}, J=4.5 \mathrm{~Hz}, \mathrm{H}-1^{\prime}\right), 4.50-4.46$ (m, 2H, H-3', H-2'), 4.23 (dd, $\left.1 \mathrm{H}, J=4.5,10.0 \mathrm{~Hz}, \mathrm{H}-4_{\mathrm{b}}^{\prime}\right), 4.10\left(\mathrm{dd}, 1 \mathrm{H}, J=2.5,10.0 \mathrm{~Hz}, \mathrm{H}-4_{\mathrm{a}}^{\prime}\right.$ ), $4.02\left(\mathrm{~s}, 3 \mathrm{H}, \mathrm{OCH}_{3}\right), 2.71\left(\mathrm{~s}, 3 \mathrm{H}, \mathrm{CH}_{3}\right) ;{ }^{13} \mathrm{C} \mathrm{NMR}(125 \mathrm{MHz}$, $\left.\mathrm{CDCl}_{3}\right): \delta 185.6(C=\mathrm{O}), 159.4(\mathrm{C}-4), 152.1$ (C-1), $148.3(\mathrm{Ar}-\mathrm{C})$, $143.6(\mathrm{COCH}=\mathrm{CH}), 136.7,128.6,128.0,127.3(\mathrm{Ar}-\mathrm{C}), 123.6$ $(\mathrm{COCH}=\mathrm{CH}), 122.5(\mathrm{C}-2), 121.5,113.1,113.0,111.5,109.5(\mathrm{Ar}-$ C), 108.5 (C-3), $81.2\left(\mathrm{C}-1^{\prime}\right), 80.1\left(\mathrm{C}-2^{\prime}\right), 78.2\left(\mathrm{C}-3^{\prime}\right), 73.5\left(\mathrm{C}-4^{\prime}\right), 71.2$ $\left(\mathrm{PhCH}_{2}\right), 55.9\left(\mathrm{OCH}_{3}\right), 14.6\left(\mathrm{CH}_{3}\right)$; ESI-MS: $473.1[\mathrm{M}+\mathrm{Na}]^{+}$; anal. calcd for $\mathrm{C}_{26} \mathrm{H}_{26} \mathrm{O}_{7}$ (450.48): C, 69.32; H, 5.82\%; found: C, 69.20; H, 5.95\%.

Compound 29. Yellow oil; $R_{\mathrm{f}}: 0.40$ (hexane-EtOAc; $1: 1$ ); $[\alpha]_{\mathrm{D}}^{25}+26\left(c 1.0, \mathrm{CHCl}_{3}\right) ;{ }^{1} \mathrm{H} \mathrm{NMR}\left(500 \mathrm{MHz}, \mathrm{CDCl}_{3}\right): \delta 8.58(\mathrm{~s}, 1 \mathrm{H}$, Ar-H), 8.57 (dd, $1 \mathrm{H}, J=1.0,8.0 \mathrm{~Hz}, \mathrm{Ar}-\mathrm{H}), 7.99$ (dd, $1 \mathrm{H}, J=3.0$, $7.5 \mathrm{~Hz}, \mathrm{Ar}-\mathrm{H}), 7.87$ (d, 1H, $=15.5 \mathrm{~Hz}, \mathrm{COCH}=\mathrm{CH}), 7.73(\mathrm{t}, 1 \mathrm{H}$, $J=7.5,8.0 \mathrm{~Hz}, \mathrm{Ar}-\mathrm{H}), 7.40(\mathrm{~d}, 1 \mathrm{H}, J=15.5 \mathrm{~Hz}, \mathrm{COCH}=\mathrm{CH}), 6.90$ (s, $1 \mathrm{H}, \mathrm{H}-3), 5.57$ (d, $\left.1 \mathrm{H}, J=3.0 \mathrm{~Hz}, \mathrm{H}-2^{\prime}\right), 5.36-5.34(\mathrm{~m}, 1 \mathrm{H}, \mathrm{H}-$ $\left.3^{\prime}\right), 4.91\left(\mathrm{~d}, 1 \mathrm{H}, J=4.0 \mathrm{~Hz}, \mathrm{H}-1^{\prime}\right), 4.33(\mathrm{dd}, 1 \mathrm{H}, J=5.0,10.5 \mathrm{~Hz}$, $\mathrm{H}-4_{\mathrm{a}}^{\prime}$ ), 4.20 (dd, $\left.1 \mathrm{H}, J=2.0,11.5 \mathrm{~Hz}, \mathrm{H}^{-} 4_{\mathrm{b}}^{\prime}\right), 2.77\left(\mathrm{~s}, 3 \mathrm{H}, \mathrm{CH}_{3}\right.$ ), 2.24, 2.23 (2 s, 6H, CH $\left.H_{3} \mathrm{CO}\right) ;{ }^{13} \mathrm{C} \mathrm{NMR}\left(125 \mathrm{MHz}, \mathrm{CDCl}_{3}\right): \delta 184.7$ $(C=\mathrm{O}), 158.7(\mathrm{C}-4), 149.8(\mathrm{C}-1), 140.2(\mathrm{COCH}=\mathrm{CH}), 136.8$, 134.2, 129.9, 126.3, $124.5(\mathrm{Ar}-\mathrm{C}), 122.2(\mathrm{COCH}=\mathrm{CH}), 122.0(\mathrm{C}-$ 2), 109.2 (C-3), 108.7 (Ar-C), 79.7 (C-1'), $78.4\left(\mathrm{C}-2^{\prime}\right), 77.9\left(\mathrm{C}-3^{\prime}\right)$, 72.0 (C-4'), 20.8, 20.5 (2C, $\left.\mathrm{CH}_{3} \mathrm{CO}\right), 14.7\left(\mathrm{CH}_{3}\right)$; ESI-MS: 466.1 [M $+\mathrm{Na}^{+}$; anal. calcd for $\mathrm{C}_{22} \mathrm{H}_{21} \mathrm{NO}_{9}$ (443.40): C, 59.59; $\mathrm{H}, 4.77 \%$; found: $\mathrm{C}, 59.45 ; \mathrm{H}, 4.90 \%$.

Compound 30. Yellow oil; $R_{\mathrm{f}}: 0.23$ (hexane-EtOAc; $1: 3$ ); $[\alpha]_{\mathrm{D}}^{25}+29\left(c 1.0, \mathrm{CHCl}_{3}\right) ;{ }^{1} \mathrm{H} \mathrm{NMR}\left(500 \mathrm{MHz}, \mathrm{CDCl}_{3}\right): \delta 7.73(\mathrm{~d}, 1 \mathrm{H}$, $J=15.5 \mathrm{~Hz}, \mathrm{COCH}=\mathrm{CH}), 7.58-7.23(\mathrm{~m}, 7 \mathrm{H}, \mathrm{Ar}-\mathrm{H}), 7.05(\mathrm{~d}, 1 \mathrm{H}, J$ $=15.5 \mathrm{~Hz}, \mathrm{COCH}=\mathrm{CH}), 7.01(\mathrm{~d}, 1 \mathrm{H}, J=2.0 \mathrm{~Hz}, \mathrm{Ar}-\mathrm{H}), 6.99(\mathrm{~s}$, $1 \mathrm{H}, \mathrm{H}-3$ ), 5.58 (d, $\left.1 \mathrm{H}, J=3.0 \mathrm{~Hz}, \mathrm{H}-2^{\prime}\right), 5.34$ (dd, $1 \mathrm{H}, J=2.5$, $4.5 \mathrm{~Hz}, \mathrm{H}-3^{\prime}$ ), 5.29 (brs, $2 \mathrm{H}, \mathrm{PhCH}_{2}$ ), 4.91 (d, $1 \mathrm{H}, J=4.0 \mathrm{~Hz}, \mathrm{H}-$ $1^{\prime}$ ), $4.32\left(\mathrm{dd}, 1 \mathrm{H}, J=5.0,10.5 \mathrm{~Hz}, \mathrm{H}-4^{\prime}{ }_{\mathrm{a}}\right.$ ), $4.18(\mathrm{dd}, 1 \mathrm{H}, J=2.0$, $\left.12.5 \mathrm{~Hz}, \mathrm{H}-4_{\mathrm{b}}^{\prime}\right), 4.05\left(\mathrm{~s}, 3 \mathrm{H}, \mathrm{OCH}_{3}\right), 2.72\left(\mathrm{~s}, 3 \mathrm{H}, \mathrm{CH}_{3}\right), 2.23,2.20$ $\left(2 \mathrm{~s}, 6 \mathrm{H}, \mathrm{CH}_{3} \mathrm{CO}\right) ;{ }^{13} \mathrm{C} \mathrm{NMR}\left(125 \mathrm{MHz}, \mathrm{CDCl}_{3}\right): \delta 185.2(\mathrm{C}=\mathrm{O})$, 
170.0, $169.5\left(\mathrm{CH}_{3} \mathrm{CO}\right), 159.5$ (C-4), 152.0 (C-1), 148.3, 147.1 (ArC), $143.3(\mathrm{COCH}=\mathrm{CH}), 136.8,128.6,128.0,127.6,127.3(\mathrm{Ar}-$ C), $123.4(\mathrm{COCH}=\mathrm{CH}), 122.5(\mathrm{C}-2), 121.6,113.2,111.5(\mathrm{Ar}-\mathrm{C})$,

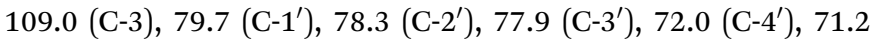
$\left(\mathrm{PhCH}_{2}\right), 55.9\left(\mathrm{OCH}_{3}\right)$, 14.6 $\left(\mathrm{CH}_{3}\right)$; ESI-MS: $557.1[\mathrm{M}+\mathrm{Na}]^{+}$; anal. calcd for $\mathrm{C}_{30} \mathrm{H}_{30} \mathrm{O}_{9}$ (534.55): C, 67.41; $\mathrm{H}, 5.66 \%$; found: $\mathrm{C}, 67.31$; $\mathrm{H}, 5.70 \%$.

Compound 31. Yellow solid; $R_{\mathrm{f}}: 0.18$ (hexane-EtOAc; $1: 3$ ); $\mathrm{mp} 99-101{ }^{\circ} \mathrm{C}[\mathrm{EtOH}] ;[\alpha]_{\mathrm{D}}^{25}+13\left(c 1.0, \mathrm{CHCl}_{3}\right) ;{ }^{1} \mathrm{H}$ NMR $(500$ $\left.\mathrm{MHz}, \mathrm{CDCl}_{3}\right): \delta 7.70(\mathrm{~d}, 1 \mathrm{H}, J=15.5 \mathrm{~Hz}, \mathrm{COCH}=\mathrm{CH}), 7.56(\mathrm{~d}$, $1 \mathrm{H}, J=7.5 \mathrm{~Hz}, \mathrm{Ar}-\mathrm{H}), 7.49$ (t, 2H, $J=8.0,7.5 \mathrm{~Hz}, \mathrm{Ar}-\mathrm{H}), 7.41$ (d, $1 \mathrm{H}, J=7.5 \mathrm{~Hz}, \mathrm{Ar}-\mathrm{H}), 7.27$ (d, $1 \mathrm{H}, J=8.0 \mathrm{~Hz}, \mathrm{Ar}-\mathrm{H}), 7.22$ (d, 1H, $=2.0 \mathrm{~Hz}, \mathrm{Ar}-\mathrm{H}), 7.03(\mathrm{~d}, 1 \mathrm{H}, J=15.5 \mathrm{~Hz}, \mathrm{COCH}=\mathrm{CH}), 6.97(\mathrm{~d}$, $1 \mathrm{H}, J=8.5 \mathrm{~Hz}$, Ar-H), 6.80 (s, 1H, H-3), 5.27 (brs, $2 \mathrm{H}, \mathrm{PhCH}_{2}$ ), $4.83\left(\mathrm{~d}, 1 \mathrm{H}, J=5.5 \mathrm{~Hz}, \mathrm{H}-1^{\prime}\right), 4.12\left(\mathrm{~m}, 1 \mathrm{H}, \mathrm{H}-2^{\prime}\right), 4.02(\mathrm{~s}, 3 \mathrm{H}$, $\mathrm{OCH}_{3}$ ), 3.88 (dd, $\left.1 \mathrm{H}, J=3.0,12.5 \mathrm{~Hz}, \mathrm{H}-3^{\prime}{ }_{\mathrm{a}}\right), 3.76(\mathrm{dd}, 1 \mathrm{H}, J=$ 5.5, $12.5 \mathrm{~Hz}, \mathrm{H}-3^{\prime}{ }_{\mathrm{b}}$ ), 2.69 (s, 3H, $\left.\mathrm{CH}_{3}\right) ;{ }^{13} \mathrm{C}$ NMR $(125 \mathrm{MHz}$, $\left.\mathrm{CDCl}_{3}\right): \delta 185.7(C=\mathrm{O}), 158.9(\mathrm{C}-4), 152.1(\mathrm{C}-1), 151.3,148.3(\mathrm{Ar}-$ C), $143.5(\mathrm{COCH}=\mathrm{CH}), 136.7,128.6,128.0,127.5,127.3(\mathrm{Ar}-\mathrm{C})$, $123.5(\mathrm{COCH}=\mathrm{CH}), 122.0(\mathrm{C}-2), 121.5,113.1,111.5(\mathrm{Ar}-\mathrm{C}), 108.1$ (C-3), $72.9\left(\mathrm{C}-1^{\prime}\right), 71.2\left(\mathrm{PhCH}_{2}\right), 68.3\left(\mathrm{C}-2^{\prime}\right), 63.5\left(\mathrm{C}-3^{\prime}\right), 55.9$ $\left(\mathrm{OCH}_{3}\right), 14.5\left(\mathrm{CH}_{3}\right)$; ESI-MS: $461.1[\mathrm{M}+\mathrm{Na}]^{+}$; anal. calcd for $\mathrm{C}_{25} \mathrm{H}_{26} \mathrm{O}_{7}$ (438.47): C, 68.48; H, 5.98\%; found: C, 68.30; H, $6.13 \%$.

Compound 32. Yellow solid; $R_{\mathrm{f}}: 0.15$ (hexane-EtOAc; $1: 3$ ); $\mathrm{mp} 94-96{ }^{\circ} \mathrm{C}[\mathrm{EtOH}] ;[\alpha]_{\mathrm{D}}^{25}+7\left(c 1.0, \mathrm{CHCl}_{3}\right) ;{ }^{1} \mathrm{H} \mathrm{NMR}(500 \mathrm{MHz}$, $\mathrm{CDCl}_{3}$ ): $\delta 8.44$ (s, $\left.1 \mathrm{H}, \mathrm{Ar}-\mathrm{H}\right), 8.22(\mathrm{~d}, 1 \mathrm{H}, J=8.0 \mathrm{~Hz}, \mathrm{Ar}-\mathrm{H}), 7.85$ $(\mathrm{d}, 1 \mathrm{H}, J=8.5 \mathrm{~Hz}, \mathrm{Ar}-\mathrm{H}), 7.73(\mathrm{~d}, 1 \mathrm{H}, J=15.5 \mathrm{~Hz}, \mathrm{COCH}=\mathrm{CH})$, $7.58(\mathrm{t}, 1 \mathrm{H}, J=8.0,8.5 \mathrm{~Hz}, \mathrm{Ar}-\mathrm{H}), 7.26(\mathrm{~d}, 1 \mathrm{H}, J=15.5 \mathrm{~Hz}, \mathrm{COCH}$ $=\mathrm{CH}), 6.74(\mathrm{~s}, 1 \mathrm{H}, \mathrm{H}-3), 4.72\left(\mathrm{~d}, 1 \mathrm{H}, J=5.0 \mathrm{~Hz}, \mathrm{H}-1^{\prime}\right), 3.99-3.79$ $\left(\mathrm{m}, 1 \mathrm{H}, \mathrm{H}-2^{\prime}\right), 3.88\left(\mathrm{dd}, 1 \mathrm{H}, J=3.0,12.5 \mathrm{~Hz}, \mathrm{H}-3^{\prime}{ }_{\mathrm{a}}\right), 3.76(\mathrm{dd}, 1 \mathrm{H}$, $\left.J=5.5,12.5 \mathrm{~Hz}, \mathrm{H}-3^{\prime}{ }_{\mathrm{b}}\right), 2.68\left(\mathrm{~s}, 3 \mathrm{H}, \mathrm{CH}_{3}\right) ;{ }^{13} \mathrm{C}$ NMR $(125 \mathrm{MHz}$, $\left.\mathrm{CDCl}_{3}\right): \delta 185.6(C=\mathrm{O}), 158.7(\mathrm{C}-4), 149.8(\mathrm{C}-1), 139.9(\mathrm{COCH}=$ $\mathrm{CH}), 135.5,133.6,129.6,126.3,124.2(\mathrm{Ar}-\mathrm{C}), 123.5(\mathrm{COCH}=$ $\mathrm{CH}$ ), 122.1 (C-2), 107.5 (C-3), $72.8\left(\mathrm{C}-1^{\prime}\right), 68.4\left(\mathrm{C}-2^{\prime}\right), 63.3\left(\mathrm{C}-3^{\prime}\right)$, $14.4\left(\mathrm{CH}_{3}\right)$; ESI-MS: $370.26[\mathrm{M}+\mathrm{Na}]^{+}$; anal. calcd for $\mathrm{C}_{17} \mathrm{H}_{17} \mathrm{NO}_{7}$ (347.32): C, 58.79; H, 4.93\%; found: C, 58.62; H, 5.10\%.

Compound 33. Yellow oil; $R_{\mathrm{f}}: 0.38$ (hexane-EtOAc; $1: 1$ ); $[\alpha]_{\mathrm{D}}^{25}+12\left(c 1.0, \mathrm{CHCl}_{3}\right) ;{ }^{1} \mathrm{H}$ NMR $\left(500 \mathrm{MHz}, \mathrm{CDCl}_{3}\right): \delta 7.73(\mathrm{~d}, 1 \mathrm{H}$, $J=15.5 \mathrm{~Hz}, \mathrm{COCH}=\mathrm{CH}), 7.59(\mathrm{~d}, 2 \mathrm{H}, J=7.0 \mathrm{~Hz}, \mathrm{Ar}-\mathrm{H}), 7.52(\mathrm{t}$, $2 \mathrm{H}, J=7.5 \mathrm{~Hz}$ each, Ar-H), 7.45 (d, 1H, $J=7.0 \mathrm{~Hz}, \mathrm{Ar}-\mathrm{H}), 7.30$ (dd, $1 \mathrm{H}, J=1.5,8.5 \mathrm{~Hz}, \mathrm{Ar}-\mathrm{H}), 7.25$ (d, 1H, $J=2.0 \mathrm{~Hz}, \mathrm{Ar}-\mathrm{H}), 7.02$ $(\mathrm{d}, 1 \mathrm{H}, J=15.5 \mathrm{~Hz}, \mathrm{COCH}=\mathrm{CH}), 7.01(\mathrm{~d}, 1 \mathrm{H}, J=8.5 \mathrm{~Hz}, \mathrm{Ar}-\mathrm{H})$, $6.87(\mathrm{~s}, 1 \mathrm{H}, \mathrm{H}-3), 6.15\left(\mathrm{~d}, 1 \mathrm{H}, J=8.0 \mathrm{~Hz}, \mathrm{H}-1^{\prime}\right), 5.70-5.68(\mathrm{~m}, 1 \mathrm{H}$, $\mathrm{H}-2^{\prime}$ ), 5.31 (brs, $2 \mathrm{H}, \mathrm{PhCH}_{2}$ ), 4.48 (dd, $1 \mathrm{H}, J=8.5,12.5 \mathrm{~Hz}, \mathrm{H}-$ $\left.3^{\prime}{ }_{\mathrm{a}}\right), 4.05-4.02\left(\mathrm{~m}, 4 \mathrm{H}, \mathrm{OCH}_{3}, \mathrm{H}^{-} 3^{\prime}{ }_{\mathrm{b}}\right), 2.74\left(\mathrm{~s}, 3 \mathrm{H}, \mathrm{CH}_{3}\right), 2.2,2.18$ $\left(2 \mathrm{~s}, 6 \mathrm{H}, \mathrm{CH}_{3} \mathrm{CO}\right) ;{ }^{13} \mathrm{C} \mathrm{NMR}\left(125 \mathrm{MHz}, \mathrm{CDCl}_{3}\right): \delta 184.9(\mathrm{C}=\mathrm{O})$, 170.1, 169.7, 169.4 (3C, $\mathrm{CH}_{3} \mathrm{CO}$ ), 159.9 (C-4), 152.1 (C-1), 148.4, 146.3 (Ar-C), $143.5(\mathrm{COCH}=\mathrm{CH}), 136.8,128.6,128.0,127.3(\mathrm{Ar}-$ C), $123.5(\mathrm{COCH}=\mathrm{CH}), 122.5(\mathrm{C}-2), 121.4,113.0,111.5(\mathrm{Ar}-\mathrm{C})$, $110.6(\mathrm{C}-3), 71.2\left(\mathrm{PhCH}_{2}\right), 70.2\left(\mathrm{C}-1^{\prime}\right), 66.4\left(\mathrm{C}-2^{\prime}\right), 62.0\left(\mathrm{C}-3^{\prime}\right)$, $55.9\left(\mathrm{OCH}_{3}\right), 20.8,20.7,20.6\left(3 \mathrm{C}, \mathrm{CH}_{3} \mathrm{CO}\right), 14.5\left(\mathrm{CH}_{3}\right)$; ESI-MS: $587.2[\mathrm{M}+\mathrm{Na}]^{+}$; anal. calcd for $\mathrm{C}_{31} \mathrm{H}_{32} \mathrm{O}_{10}$ (564.58): C, 65.95; $\mathrm{H}, 5.71 \%$; found: C, 65.86; $\mathrm{H}, 5.89 \%$.

Compound 34. Yellow oil; $R_{\mathrm{f}}$ : 0.44 (hexane-EtOAc; $1: 1$ ); $[\alpha]_{\mathrm{D}}^{25}+11\left(c 1.0, \mathrm{CHCl}_{3}\right) ;{ }^{1} \mathrm{H} \mathrm{NMR}\left(500 \mathrm{MHz}, \mathrm{CDCl}_{3}\right): \delta 8.48(\mathrm{~s}, 1 \mathrm{H}$, $\mathrm{Ar}-\mathrm{H}), 8.26$ (d, 1H, $J=8.0 \mathrm{~Hz}, \mathrm{Ar}-\mathrm{H}), 7.89$ (d, 1H, $J=7.5 \mathrm{~Hz}, \mathrm{Ar}-$
$\mathrm{H}), 7.75(\mathrm{~d}, 1 \mathrm{H}, J=15.5 \mathrm{~Hz}, \mathrm{COCH}=\mathrm{CH}), 7.62(\mathrm{t}, 1 \mathrm{H}, J=8.0 \mathrm{~Hz}$ each, Ar-H), $7.28(\mathrm{~d}, 1 \mathrm{H}, J=15.5 \mathrm{~Hz}, \mathrm{COCH}=\mathrm{CH}), 6.85(\mathrm{~s}, 1 \mathrm{H}$, $\mathrm{H}-3), 6.02$ (d, 1H, $\left.J=3.5 \mathrm{~Hz}, \mathrm{H}-1^{\prime}\right), 5.53-5.50$ (m, 1H, H-2'), 4.43 $\left(\mathrm{dd}, 1 \mathrm{H}, J=3.0,12.5 \mathrm{~Hz}, \mathrm{H}-3^{\prime}{ }_{\mathrm{a}}\right.$ ), $3.94(\mathrm{dd}, 1 \mathrm{H}, J=5.5,12.0 \mathrm{~Hz}, \mathrm{H}-$ $\left.3^{\prime}{ }_{\mathrm{b}}\right), 2.68\left(\mathrm{~s}, 3 \mathrm{H}, \mathrm{CH}_{3}\right), 2.12,2.11,2.09\left(3 \mathrm{~s}, 9 \mathrm{H}, \mathrm{CH}_{3} \mathrm{CO}\right) ;{ }^{13} \mathrm{C} \mathrm{NMR}$ $\left(125 \mathrm{MHz}, \mathrm{CDCl}_{3}\right): \delta 183.8(C=\mathrm{O}), 170.0,169.8,169.1$ (3C, $\left.\mathrm{CH}_{3} \mathrm{CO}\right), 160.6(\mathrm{C}-4), 148.7(\mathrm{C}-1), 140.3(\mathrm{COCH}=\mathrm{CH}), 136.4$, 133.9, 129.7, 127.9, 126.0, $125.5(\mathrm{Ar}-\mathrm{C}), 122.2(\mathrm{COCH}=\mathrm{CH})$, 122.8 (C-2), 110.5 (C-3), $70.1\left(\mathrm{C}-1^{\prime}\right), 66.1\left(\mathrm{C}-2^{\prime}\right), 61.6\left(\mathrm{C}-3^{\prime}\right), 20.7$, 20.6, 20.5 (3C, $\left.\mathrm{CH}_{3} \mathrm{CO}\right), 14.6\left(\mathrm{CH}_{3}\right)$; ESI-MS: $496.1[\mathrm{M}+\mathrm{Na}]^{+}$; anal. calcd for $\mathrm{C}_{23} \mathrm{H}_{23} \mathrm{NO}_{10}$ (473.43): C, 58.35; H, 4.90\%; found: C, 58.47; H, 5.10\%.

\section{MTT cell proliferation assay}

The anti-proliferative effects of the $C$-glycosyl-3-cinnamoylfuran derivatives (7-34) were assessed by a MTT proliferation assay. ${ }^{26}$ For this experiment, cells were seeded in triplicate in 96 well plates and incubated overnight. Post incubation cells were treated with compounds at various concentrations $(5 \mu \mathrm{M}, 10$ $\mu \mathrm{M}, 20 \mu \mathrm{M}$ and $50 \mu \mathrm{M})$ for $48 \mathrm{~h}$. After the treatment, $200 \mu \mathrm{l}$ of MTT solution $\left(0.5 \mathrm{mg} \mathrm{ml} \mathrm{m}^{-1}\right)$ were added to each well and incubated at $37{ }^{\circ} \mathrm{C}$ for $3 \mathrm{~h}$. Subsequently, the MTT media was discarded and purple colored formazan crystals were dissolved using DMSO. The absorbance was measured at $570 \mathrm{~nm}$ in a 96 well micro-plate reader (Thermo, Multiskan Go).

\section{Clonogenic survival assay}

In 6 well plates around $200 \mathrm{MCF}$-cells were seeded in each of the wells and cells were allowed to attach to the plates for $2 \mathrm{~h}$. Then the cells were treated with different concentrations of compound 24 ( $0 \mathrm{nM}, 100 \mathrm{nM}, 500 \mathrm{nM}, 1.25 \mu \mathrm{M}, 2.5 \mu \mathrm{M}$ and 5 $\mu \mathrm{M})$ for the next 15 days with continuous change of media on every $3^{\text {rd }}$ day with or without compounds. After 15 days the cells were washed with 1X PBS and incubated with $3 \mathrm{ml}$ of a mixture of $3.7 \%$ formaldehyde in $1 \mathrm{X}$ PBS and $0.5 \%$ crystal violet for 30 minutes. The formaldehyde crystal violet mixture was carefully removed by rinsing with tap water and plates were allowed to dry at room temperature. Finally, the image was captured using Gel Doc XR + (Bio-Rad) and colony numbers were counted.

\section{Cell cycle arrest assay by propidium iodide staining}

MCF-7 cells were treated with increasing concentrations $(0,5$ $\mu \mathrm{M}, 10 \mu \mathrm{M}, 20 \mu \mathrm{M}, 30 \mu \mathrm{M})$ of compound 24 for $24 \mathrm{~h}$ and $2 \mu \mathrm{M}$ of nocodazole was used as a positive control for G2 arrest. Post treatment cells were converted into single cell suspension and fixed with $75 \%$ ethanol overnight at $-20{ }^{\circ} \mathrm{C}$. Cells were centrifuged and resuspended in 1X PBS for $2 \mathrm{~h}$ followed by RNase A $(20 \mu \mathrm{m})$ treatment for $2 \mathrm{~h}$ at $37^{\circ} \mathrm{C}$. Finally, propidium iodide was added and incubated for 20 minutes at room temperature. Flow cytometric analysis was immediately performed using a FACS Verse instrument (BD).

\section{Analysis of apoptosis by annexin V-FITC/PI}

To determine the apoptosis-inducing ability of compound 24 on MCF-7 cells, a double staining method with annexin V-FITC and 
PI was performed using an assay kit (BD bioscience kit). MCF-7 cells were seeded in a 6 well plate and incubated overnight followed by treatment with various concentrations of compound $24(5 \mu \mathrm{M}, 10 \mu \mathrm{M}, 20 \mu \mathrm{M}$ and $30 \mu \mathrm{M})$ for $48 \mathrm{~h}$. After treatment, the cells were washed with $1 \mathrm{X}$ PBS and resuspended in $100 \mu \mathrm{l}$ of binding buffer. Finally, cells were incubated with 5 $\mu \mathrm{l}$ of annexin V-FITC and $5 \mu \mathrm{l}$ of PI for $15 \mathrm{~min}$ at room temperature in the dark and flow cytometric analysis was performed using a BD Verse FACS machine.

\section{Proteome Profiler array}

A Human Apoptosis Array Kit from R\&D Systems (USA) was used for determining the apoptosis-related proteins following the manufacturer's protocol. Briefly, the cells were treated with compound 24 at $30 \mu \mathrm{M}$ concentration for $48 \mathrm{~h}$ and a DMSO control was kept. $250 \mu \mathrm{g}$ protein from each sample was incubated overnight with the array. Finally, the data was measured by developing the membrane and then the pixel density was calculated using Image J software. Data are representative of two independent experiments and the bar graph shows mean \pm SEM $(* p<0.05, * * p<0.01, * * * p<0.001$, ns $=$ not significant $)$.

\section{Caspase 3 activity assay}

A colorimetric assay following the manufacturer's protocol (Caspase 3 Assay Kit (Colorimetric) (ab39401)) was used to measure the caspase activity. MCF-7 cells were treated with compound 24 at a concentration of $30 \mu \mathrm{M}$ for $24 \mathrm{~h}$ and $48 \mathrm{~h}$. The RIPA buffer method was used to prepare the cell lysates. Each cell lysate was incubated with $50 \mu \mathrm{l}$ of $2 \times$ reaction buffer (containing $10 \mathrm{mM}$ DTT) and $5 \mu \mathrm{l}$ of the $4 \mathrm{mM}$ DEVD-p-NA substrate $(200 \mu \mathrm{M})$ and kept at $37^{\circ} \mathrm{C}$ for $2 \mathrm{~h}$. The OD was measured at $400 \mathrm{~nm}$ in a micro-plate reader and then the graph was plotted.

\section{Quantitative structure activity relationship (QSAR) analysis}

Based on the experimental results, the molecular structures were compared with the $\mathrm{IC}_{50}$ value to elucidate a quantitative structure-activity relationship. The 3D-QSAR module of the Schrödinger program was used to derive the atom-based analysis. All molecular structures were prepared and minimized using Maestro GUI. The models were processed by categorizing all 28 molecules into a training set and a test set. The model divides the space of grids into uniform-sized cubes that reflect the biological relationship using structural features, corresponding through positive (blue) and negative (red) contours. Characterization of molecules is performed using independent variables for structural components to reflect statistically significant results. Model building was performed using partial least-squares regression (PLS). Detailed methodology and principles are similar to the reports published earlier. ${ }^{39}$

\section{Acknowledgements}

D. D., P. P. and A. S. thank Council of Scientific and Industrial Research (CSIR), India for providing Senior Research Fellowships. This work is supported by CSIR, India [Grant No. 02(0237)/15/EMR-II (AKM)] and Bose Institute. Dr Anirban
Bhunia, Bose Institute is thankfully acknowledged for valuable discussions regarding QSAR analysis.

\section{Notes and references}

1 T. Vij, Y. Prashar and D. Jain, Int. J. Pharmacol. Res., 2014, 4, 91-102.

2 G. A. Mishra, S. A. Pimple and S. S. Shastri, Indian J. Med. Paediatr. Oncol., 2011, 32, 125-132.

3 K. Unger-Saldaña, World J. Clin. Oncol., 2014, 5, 465-477.

$4 \mathrm{~J}$. L. Markman, A. Rekechenetskiy, E. Holler and J. Y. Ljubimova, Adv. Drug Delivery Rev., 2013, 65, 1866-1879.

5 J. H. Lee and A. Nan, J. Drug Delivery, 2012, 2012, 915375.

6 N. S. Gavande, P. S. VanderVere-Carozza, H. D. Hinshaw, S. I. Jalal, C. R. Sears, K. S. Pawelczak and J. J. Turchi, Pharmacol. Ther., 2016, 160, 65-83.

7 G. Housman, S. Byler, S. Heerboth, K. Lapinska, M. Longacre, N. Snyder and S. Sarkar, Cancers, 2014, 6, 1769-1792.

8 A. L. Demain and P. Vaishnav, Microb. Biotechnol., 2011, 4, 687-699.

9 T. Kakizoe, Jpn. J. Clin. Oncol., 2003, 33, 421-442.

10 W. A. El-Sayed, M. M. M. Ramiz and A. A.-H. Abdel-Rahman, Monatsh. Chem., 2008, 139, 1499-1505.

11 W. A. El-Sayed, I. F. Nassar and A. A.-H. Abdel-Rahman, Monatsh. Chem., 2009, 140, 365-370.

12 M. M. El-Sadek, S. Y. Hassan, N. S. Abdel-Dayem and G. A. Yacout, Molecules, 2012, 17, 7010-7027.

13 L. Yan, G.-F. Dai, J.-L. Yang, F.-W. Liu and H.-M. Liu, Bioorg. Med. Chem. Lett., 2007, 17, 3454-3457.

14 E. Bokor, S. Kun, D. Goyard, M. Toth, J.-P. Praly, S. Vidal and L. Somsak, Chem. Rev., 2017, 117, 1687-1764.

15 K. Lalitha, K. Muthusamy, Y. S. Prasad, P. K. Vemula and S. Nagarajan, Carbohydr. Res., 2015, 402, 158-171.

16 G. Mugunthan, K. Ramakrishna, D. Sriram, P. Yogeeswari and K. P. R. Kartha, Bioorg. Med. Chem. Lett., 2011, 21, 3947-3950.

17 M. V. Buchieri, L. E. Riafrecha, O. M. Rodriguez, D. Vullo, H. R. Morbidoni, C. T. Supuran and P. A. Colinas, Bioorg. Med. Chem. Lett., 2013, 23, 740-743.

18 L. E. Riafrecha, O. M. Rodriguez, D. Vullo, C. T. Supuran and P. A. Colinas, Bioorg. Med. Chem., 2014, 22, 5308-5314.

19 D. Giguere, S. Andre, M.-A. Bonin, M. A. Bellefleur, A. Provencal, P. Cloutier, B. Pucci, R. Roy and H.-J. Gabius, Bioorg. Med. Chem., 2011, 19, 3280-3287.

20 D. Giguere, M.-A. Bonin, P. Cloutier, R. Patnam, C. St-Pierre, S. Sato and R. Roy, Bioorg. Med. Chem., 2008, 16, 7811-7823. 21 S. S. Bisht, S. Fatima, A. K. Tamrakar, N. Rahuja, N. Jaiswal, A. K. Srivastava and R. P. Tripathi, Bioorg. Med. Chem. Lett., 2009, 19, 2699-2703.

22 P. Roy, D. Dhara, P. K. Parida, R. K. Kar, A. Bhunia, K. Jana, S. P. Sinha Babu and A. K. Misra, Eur. J. Med. Chem., 2016, 114, 308-317.

23 A. K. Misra and G. Agnihotri, Carbohydr. Res., 2004, 339, 1381-1387.

24 J. S. Yadav, B. V. S. reddy, M. Sreenivas and G. Sathees, Synthesis, 2007, 1712-1716. 
25 A. V. Lee, S. Oesterreich and N. E. Davidson, J. Natl. Cancer Inst., 2015, 107, DOI: /10.1093/jnci/djv073.

26 J. R. Masters, Nat. Rev. Cancer, 2002, 2, 315-319.

27 M. A. Barry, J. E. Reynolds and A. Eastman, Cancer Res., 1993, 53(10), 2349-2357.

28 P. R. Twentyman and M. Luscombe, Br. J. Cancer, 1987, 56, 279-285.

29 N. A. Franken, H. M. Rodermond, J. Haveman and C. van Bree, Nat. Protoc., 2006, 1, 2315-2319.

30 R. J. Vasquez, B. Howell, A. M. Yvon, P. Wadsworth and L. Cassimeris, Mol. Biol. Cell, 1997, 8, 973-985.

31 E. Miller, Methods Mol. Med., 2004, 88, 191-202.

32 R. S. Tibbetts, K. M. Brumbaugh, J. M. Williams, J. N. Sarkaria, W. A. Cliby, S. Y. Shieh, Y. Taya, C. Prives and R. T. Abraham, Genes Dev., 1999, 13, 152-157.

33 J. Loughery, M. Cox, L. M. Smith and D. W. Meek, Nucleic Acids Res., 2014, 42, 7666-7680.
34 L. Feng, M. Hollstein and Y. Xu, Cell Cycle, 2006, 5, 28122819.

35 K. Oda, H. Arakawa, T. Tanaka, K. Matsuda, C. Tanikawa, T. Mori, H. Nishimori, K. Tamai, T. Tokino, Y. Nakamura and Y. Taya, Cell, 2000, 102, 849-862.

36 S. J. Ullrich, K. Sakaguchi, S. P. Lees-Miller, M. Fiscella, W. E. Mercer, C. W. Anderson and E. Appella, Proc. Natl. Acad. Sci. U. S. A., 1993, 90, 5954-5958.

37 B. B. Wolf, M. Schuler, F. Echeverri and D. R. Green, J. Biol. Chem., 1999, 274, 30651-30656.

38 S. L. Dixon, A. M. Smondyrev, E. H. Knoll, S. N. Rao, D. E. Shaw and R. A. Friesner, J. Comput.-Aided Mol. Des., 2006, 20, 647-671.

39 R. K. Kar, P. Suryadevara, B. R. Sahoo, G. C. Sahoo, M. R. Dikhit and P. Das, SAR QSAR Environ. Res., 2013, 24, 215-234. 